\title{
Forest fragmentation mapping, change detection, and gas well site identification in remotely sensed imagery: the role of spatial resolution
}

\author{
Benjamin A. Baker \\ West Virginia University
}

Follow this and additional works at: https://researchrepository.wvu.edu/etd

\author{
Recommended Citation \\ Baker, Benjamin A., "Forest fragmentation mapping, change detection, and gas well site identification in \\ remotely sensed imagery: the role of spatial resolution" (2012). Graduate Theses, Dissertations, and \\ Problem Reports. 700. \\ https://researchrepository.wvu.edu/etd/700
}

This Thesis is protected by copyright and/or related rights. It has been brought to you by the The Research Repository @ WVU with permission from the rights-holder(s). You are free to use this Thesis in any way that is permitted by the copyright and related rights legislation that applies to your use. For other uses you must obtain permission from the rights-holder(s) directly, unless additional rights are indicated by a Creative Commons license in the record and/ or on the work itself. This Thesis has been accepted for inclusion in WVU Graduate Theses, Dissertations, and Problem Reports collection by an authorized administrator of The Research Repository @ WVU. For more information, please contact researchrepository@mail.wvu.edu. 
Forest fragmentation mapping, change detection, and gas well site identification in remotely sensed imagery: the role of spatial resolution

Benjamin A. Baker

\author{
Thesis submitted to the \\ Eberly College of Arts and Sciences \\ at West Virginia University in \\ partial fulfillment of the requirements \\ for the degree of
}
Master of Arts
in
Geography

Timothy A. Warner, Ph.D., Chair

Jamison F. Conley, Ph. D.

Brenden E. McNeil, Ph. D.

Department of Geology and Geography

\author{
Morgantown, West Virginia \\ 2012
}

Key Words: Change detection, remote sensing, object-based, landscape metrics, scale Copyright 2012 Benjamin A. Baker 


\section{Abstract \\ Forest fragmentation mapping, change detection, and gas well site identification in remotely sensed imagery: the role of spatial resolution}

\section{Benjamin A. Baker}

This research focuses on identifying optimal data and methods for detecting and quantifying land cover/land use change associated with natural gas drilling in Appalachia. Airborne and satellite remote sensing provides a tool for examining land cover changes. Although change detection has been used in many applications related to natural and anthropogenic land cover change, little research has investigated the spatial pattern of land cover change associated with the ongoing expansion of natural gas drilling, particularly within the Marcellus Shale formation found across much of the northern Appalachian Region. Mapping land cover/land use change facilitates research of other relevant topics that require an understanding of methodological and scaling issues, particularly concerning environmental impacts of gas well drilling. I found that objectbased classification is not significantly more accurate than pixel-based classification and accuracy does not vary with spatial resolution. However, object-based classifications were qualitatively more suitable for identifying land cover change related to well clearings at finer (1 m) resolutions, whereas the pixel-based classifications had a higher percentage of correctly identified well clearings at the coarsest resolution $(30 \mathrm{~m})$. In addition to investigating classification accuracy, scaling relations of landscape metrics at fine resolutions were compared to previous research of $\mathrm{Wu}$ et al. (2002) and $\mathrm{Wu}$ (2004), and were found to be consistent with previous research. Landscape metrics were also used to test for statistically significant changes in the forested class between the 2004 and 2010 classifications. Landscape metrics derived from random quadrats sampled across the entire county produced results that differed from quadrats sampled from high and low well density areas. Changes in metrics for sample areas with low densities of new wells indicate forest area and mean patch size increased significantly. One metric - edge density (ED) — was found to be sensitive to clearings and other development (access roads) related to natural gas development in areas with higher densities of new well clearings. This research provides a foundation for future investigation into natural gas development and suggests significant changes to forested ecosystems must be observed on a finer scale than the county level to assess the ecological significance of natural gas development. 


\section{Acknowledgements}

I have had a tremendous amount of support from many people that has allowed me to complete this research.

First, I thank Dr. Warner for keeping me on track and giving me feedback on my progress and research goals that helped me improve my initial ideas. His encouragement throughout the process helped me stay focused throughout the duration of my research. I would also like to thank my committee members Dr. Jamison Conley and Dr. Brenden McNeil for their feedback and suggestions to improve my research and my writing.

My family also deserves many thanks, especially my parents, Jeff and Alice Baker, and my in-laws, Morris and Francie Henard. I thank you all for encouraging and supporting me through my personal and academic activities. I also thank my beautiful wife, Charlie, for being a constant source of encouragement, inspiration, and joy. I truly could not have completed this endeavor without your love and support. Lastly, I thank my Heavenly Father for providing me with all that I have and for always guiding my path. 


\section{Table of Contents}

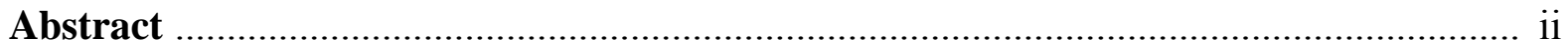

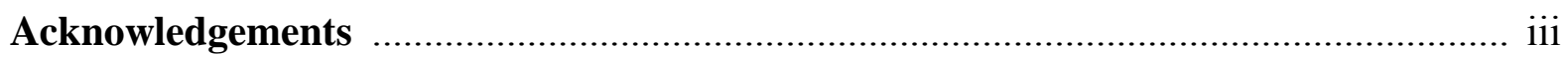

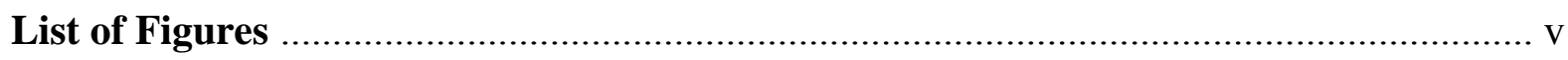

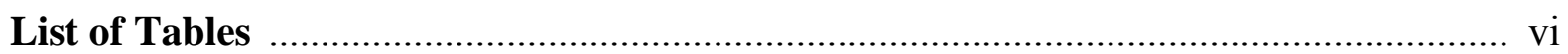

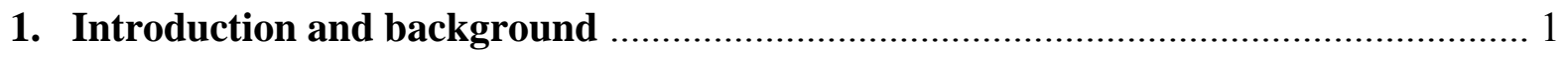

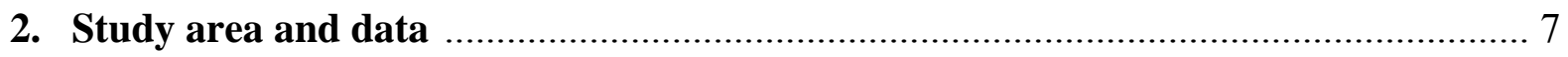

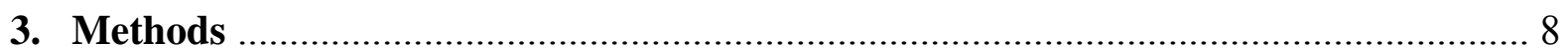

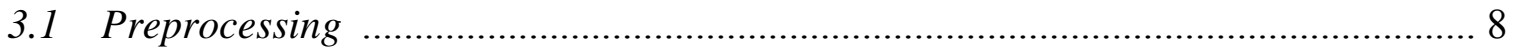

3.2 Land cover classifications ............................................................................. 9

3.3 Land cover change map accuracy assessment ................................................... 10

3.4 Land cover change of new clearings accuracy assessment .................................. 13

3.5 Landscape metrics scaling relations ................................................................ 14

3.6 Temporal change in landscape metrics ............................................................. 14

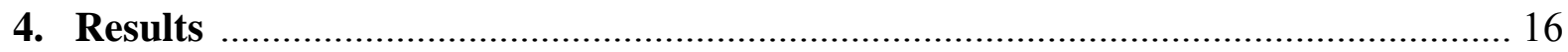

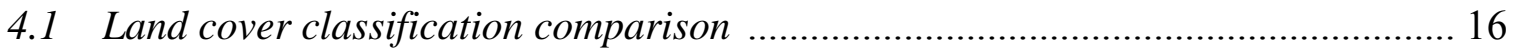

4.2 Land cover change map accuracy assessment comparison ................................... 17

4.3 Land cover change of new clearings accuracy assessment ................................... 18

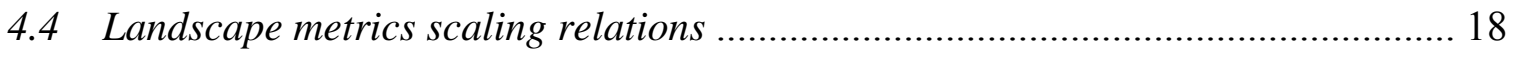

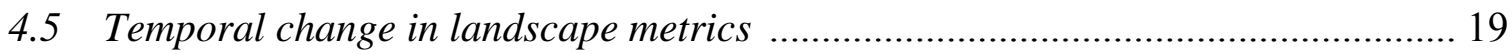

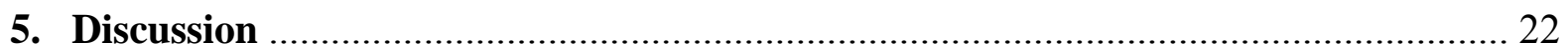

5.1 Comparison of classification methods ............................................................. 22

5.2 Accuracy of clearing identification ................................................................ 23

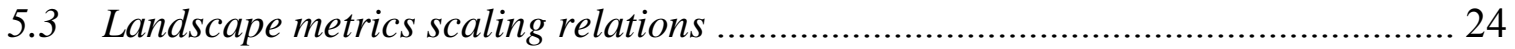

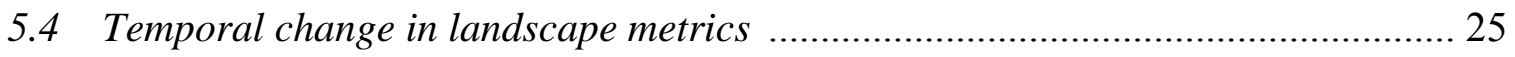

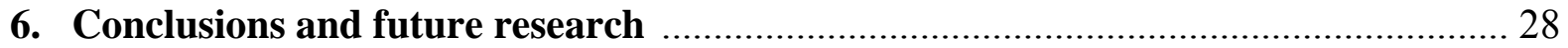

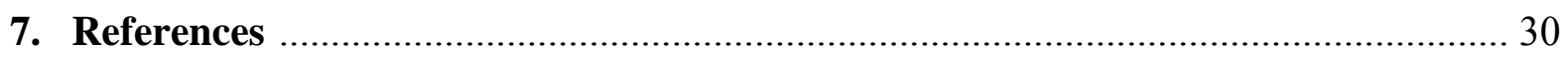

8. Appendix 1: Example object-based ruleset ...................................................... 45

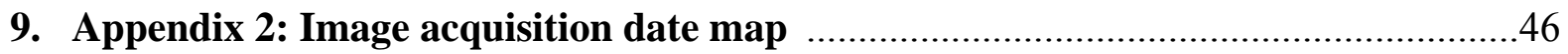




\section{List of Figures}

Figure 1. Map of study area showing active oil and gas well permit locations in Greene County, Pennsylvania. Inset map shows Greene County's location in relation to Pennsylvania and

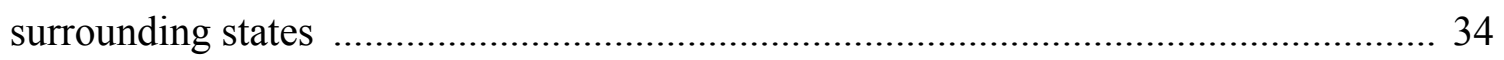

Figure 2. Standard false color infrared National Agricultural Imagery Program (NAIP) images of well locations in forested area near Jefferson, PA (a) 2004 and (b) 2010 .................... 35

Figure 3. Research flow chart showing main steps in methods and analysis ........................ 35

Figure 4. Example of object-based accuracy assessment polygon ...................................... 36

Figure 5. Comparison of original images, pixel-based, and object-based maps of land cover change at $1-30 \mathrm{~m}$ spatial resolutions ..................................................................... 37

Figure 6. Comparison of overall accuracy of land cover change maps for pixel-based and objectbased classification methods of 5 spatial resolutions ............................................. 38

Figure 7. Accuracy comparison of correctly identified land cover change of well clearings for pixel-based and object-based classification methods ............................................. 39

Figure 8. Scalograms showing landscape metric scaling relations across selected spatial resolutions ( $1 \mathrm{~m}, 2 \mathrm{~m}, 5 \mathrm{~m}, 15 \mathrm{~m}$, and $30 \mathrm{~m})$

Figure 9. Maps of changes in landscape metrics between 2004 and 2010 for classification of $5 \mathrm{~m}$

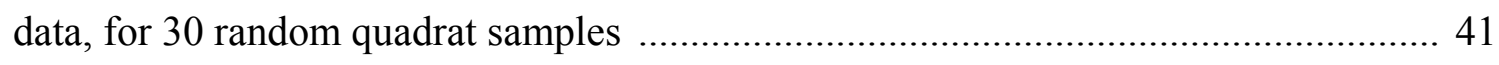

Figure 10. Example of object-based ruleset using eCognition Developer 8.64.1................... 45

Figure 11. Map of image acquisition dates by year for each $3.75^{\prime} \times 3.75^{\prime}$ quarter quadrangle within study area 46 


\section{List of Tables}

Table 1. Selected landscape metrics, definitions, and previous findings regarding scaling relations of landscape metrics at coarse resolutions

Table 2. Overall accuracy, producer's accuracy, user's accuracy, quantity disagreement, and allocation disagreement for maps of land cover

Table 3. Wilcoxon signed ranks test of landscape metric changes between 2004 and 2010 for all quadrat samples $(\mathrm{n}=30)$

Table 4. Wilcoxon signed ranks test of landscape metric changes between 2004 and 2010 for low-activity quadrat samples $(\mathrm{n}=20)$

Table 5. Wilcoxon signed ranks test of landscape metric changes between 2004 and 2010 for high-activity quadrat samples $(\mathrm{n}=10)$ 44 


\section{Introduction and background}

Anthropogenic land use change has a profound influence on the natural environment (Lausch and Herzog 2002). Land cover/land use changes (LCLUC) alter ecosystem functions and can lead to disruptions of nutrient cycling and degradation of habitat (Simmons et al. 2008, Weakland and Wood 2005). In particular, LCLUC related to natural resource extraction not only affects the natural environment but may also have implications for human health (Palmer et al. 2010, Kargbo et al. 2010). Both the magnitude and spatial distribution of land cover change are important controls on how ecosystems respond to such change.

Recent technological advancements in natural gas development, including hydraulic fracturing and horizontal drilling, have led to a rapid increase in the rate of natural gas exploration in the eastern United States (Renner 2008). The Marcellus Shale formation, underlying approximately $128000 \mathrm{~km}^{2}$ in parts of Pennsylvania, West Virginia, New York, Ohio, Virginia and Maryland, USA has become the focus of natural gas companies in this region. In Pennsylvania, this resource has been increasingly developed since 2005 (Soeder 2010), especially in southwestern Pennsylvania (Fig. 1). The large quantities of water required for hydraulic fracturing and the chemicals added to the fluid that is pumped underground pose a threat to surface water and groundwater supplies and may be linked to adverse human health consequences (Renner 2008). In addition to water quality concerns, clearing forested areas for drill pads and infrastructure also contributes to habitat fragmentation and provides new routes for

invasive species to enter natural ecosystems (Soeder 2010). Policies to regulate the growing natural shale-gas industry are struggling to catch up with these environmental concerns (Renner 2008). 
Change detection studies have been employed in numerous case studies investigating land cover change associated with resource extraction, including surface mining (e.g. Townsend et al. 2009) and logging (e.g. Franklin et al. 2002). Change analysis methods can be classified as pixel-based or object-based methods. A pixel-based approach assesses change for each pixel, independent of its neighbors. A common pixel-based method of observing land cover change is post-classification change detection. Post-classification change detection uses independently classified thematic maps followed by a geographic information systems (GIS) overlay to assess land cover change between the classifications (Jensen 2005). This method is regarded as one of the simplest approaches to change detection studies because atmospheric correction is not required (Warner et al. 2009). However, one of the major criticisms of this approach is that the error of the change analysis can be, at least in the worst case, the product of errors of the independent classifications (Rutchey and Vilcheck 1994, Arzandeh and Wang 2003). Furthermore, as with all pixel-based methods, a precise co-registration is essential (Dai and Khorram 1998).

Object-oriented change detection is based upon three steps. First, an image is segmented into image objects, which are built from groups of contiguous pixels that ideally represent real-world objects of similar digital numbers (Hay et al. 2005). This allows a more intuitive approach to image analysis as it avoids some of the challenges of an arbitrary per-pixel analysis (Blaschke 2010). Next, the segments are classified into land cover categories using a membership function classifier or a nearest neighbor classifier (Myint 2011). A membership function classifier requires an expert to create rules for classifying objects whereas a nearest neighbor classifier only requires the user to provide "training" objects for each class (Myint 2011). The final stage of an object-oriented change detection study is evaluating change. Although initially 
recommended for only fine spatial resolution applications (Lu and Weng 2007), Gamanya et al. (2009) applied an object-oriented approach to Landsat Thematic Mapper (TM) $30 \mathrm{~m}$ imagery, and achieved an overall accuracy of nearly $96 \%$. Their study also demonstrated how this method might be applied to multiple images to identify how an object (polygon) present in the original image has changed over time (Gamanya et al. 2009). A recent study has also shown how the incorporation of ancillary vector layers can further improve object-based classification accuracy (Newman et al. 2011).

An important consideration for detecting small features in a change analysis is the resolution at which the features of interest can be identified. First, the minimum spatial resolution for accurately identifying a feature must be considered. Hengl (2006) suggests at least four pixels are needed to detect small objects, although others suggest detection is possible with a smaller number (Cracknell 1998). For example, while some well clearings associated with gas wells are readily apparent on localized, high resolution imagery (e.g. Fig. 2), detecting clearings associated with wells using coarser resolution imagery—such as NASA's Advanced Spaceborne Thermal Emission and Reflection Radiometer (ASTER) or Landsat—would greatly facilitate the detection of land-cover change across the broader Appalachian region. In addition to spatial resolution, the position of an object with respect to the grid of pixels also influences how well a feature on the ground may be detected (Lechner et al. 2009). A feature that is contained mostly within a single pixel is more likely to be detected than an object located at the intersection of four pixels. Furthermore, identifying real change rather than artifacts due to misalignment from one image date to another is also a major concern when using multiple images (Dai and Khorram 1998). Habitat fragmentation resulting from land use/land cover change has been identified as one of the major causes of decreased biodiversity (Wilcox and Murphy 1985). Landscape metrics 
provide another set of tools that may be useful for quantifying how a landscape has changed (Betts et al. 2003). For example, a study by Robbins et al. (1989) showed that the probability of some avian species, (e.g. the Louisiana Waterthrush) being present in forested areas is a function of the size and perimeter/area ratio of forested patches.

Although calculating landscape metrics has proven to be a useful method for studying fragmentation, values are often scale dependent, and affected by the grain (pixel resolution) and extent (geographic area) (Wu et al. 2002). Landscape metrics are a product of the thematic data used for calculating metrics, and therefore errors within classifications may be propagated to the subsequent metrics (Shao and Wu 2008). The use of landscape metrics to quantify changes in a landscape has been shown to have limitations; however, metrics remain in use because of the ease of calculation and their intuitive nature, but must be linked to real landscape structure and processes to be of any use to researchers (Kupfer in press).

One of the major focuses of research in the scale-dependency of landscape metrics is the expected change in class-level and landscape-level landscape indices across different spatial resolutions (Benson and MacKenzie 1995, Wu et al. 2002, Wu 2004). A study by Benson and MacKenzie (1995) used three different satellite-borne sensors-Système Pour l'Observation de la Terre (SPOT) High Resolution Visible, with $20 \mathrm{~m}$ resolution, Landsat TM with $30 \mathrm{~m}$ resolution, and Advanced Very High Radiometer Resolution (AVHRR) with 1.1 km resolutionto show that as spatial resolution coarsens the number of measured patches decreases while the average patch area increases. They used a two-class thematic map, with water bodies as the land cover class of interest. Additionally, they found that using a majority rule to aggregate classifications to coarser resolutions and derive landscape metrics was an acceptable approximation for estimating landscape metrics from classifications produced using imagery at 
coarser spatial resolutions (Benson and MacKenzie 1995). An empirical investigation by Wu et al. (2002) identified three types of pattern effects for 19 different landscape-level metrics when grain, extent, and direction of analysis were changed. Metrics they termed "Type I" had predictable, simple scaling relationships with increasing grain size. "Type II" metrics had stairlike changes with increasing grain, and "Type III" metrics showed no consistent responses. Another study by $\mathrm{Wu}$ (2004) classified two scaling relations for 17 class-level metrics as either predictable or unpredictable. Thus, a better understanding of how metrics may change over varying spatial resolutions help to predict landscape metrics at resolutions different from the classified data. The image of Fig. 2 (b) clearly shows not only forest cut for gas well clearings, but also for the access roads leading to these clearing. This type of fine-scale fragmentation may be less apparent in classifications produced at resolutions similar to or coarser than the width of these roads.

Another focus of landscape metrics research is the use of such metrics as proxy indices for measuring landscape change. For example, Lausch and Herzog (2002) investigated the use of selected landscape metrics for observing landscape pattern over time. Other studies have also used landscape metrics to quantify trends in landscape patterns over time, focusing especially on forest fragmentation (Southworth et al. 2002, Griffith et al. 2003, Ferraz et al. 2006). These studies have focused on the ability to characterize a landscape using satellite imagery and to understand and identify possible impacts of ecological and human processes (Southworth et al. 2002, Griffith et al. 2003). Ferraz et al. (2006) investigated how landscape metrics changed at specific time intervals and resolutions, ranging from $30-270 \mathrm{~m}$, to test for significant changes in metrics between intervals and resolutions. 
In my research, I focus on a comparison of a pixel-based and object-based classification method for characterizing land cover change across five spatial resolutions. The optimal resolutions and method for identifying well clearings is of primary interest for monitoring land cover change associated with natural gas development. In addition to classification accuracy, this study investigates scaling relations of landscape metrics using fine to moderate resolution imagery in the Appalachian region and looks for signs of statistically significant changes in these metrics as a result of natural gas development. Mapping land cover/land use change facilitates research of other relevant topics that require an understanding of methodological and scaling issues, particularly concerning environmental impacts of gas well drilling. My research aims to answer the following specific questions in the context of the case study:

1. Is an object-based classification approach a more accurate method than a pixel-based approach for identifying land cover change associated with natural gas development?

2. What are the best spatial resolutions and classification methods for accurately identifying the extent of well clearings within forested areas?

3. How do derived landscape metrics regarding forest fragmentation in this region compare over time and spatial resolution?

Through the simulation of images of different spatial scales, this research has implications for change detection studies using sensors that range from high resolution (e.g. QuickBird) to moderate resolution (e.g. Landsat ETM). This research thus serves as a foundation for further investigation into natural gas development and its impacts on local ecosystems, and may be tailored to species-specific habitat evaluations in the future. 


\section{Study area and data}

The study area of this research is Greene County, Pennsylvania, in the southwestern corner of Pennsylvania, bordered to the west and south by West Virginia (Fig. 1). The county covers approximately $1500 \mathrm{~km}^{2}$ and has a population of 40672 , nearly 70 percent of whom live in areas designated as rural (United States Census Bureau 2000).

Two different dates of $1 \mathrm{~m}$ pixel size National Aerial Imagery Program (NAIP) imagery formed the primary dataset. A set of images for Greene County acquired in 2004 and another in 2010 were purchased from the USDA Aerial Photography Field Office (APFO, http://www.apfo.usda.gov/). The 2004 3.75" quarter quadrangles were collected during the leafon season of 2004, with bands in the green, red, and near infrared regions of the electromagnetic spectrum. The image acquisition dates range between 20 June 2004 and 3 September 2004, with the exception of one quarter quadrangle on the edge of the study area which was collected on 7 October 2004. The 2010 quarter quadrangle image tiles were collected between 18 June 2010 and 2 September 2010 and are composed of blue, green, red, and near infrared bands. An ancillary point dataset containing all active oil and gas well permit locations available from the Pennsylvania Spatial Data Access (PASDA, http://www.pasda.psu.edu/default.asp) was used as a reference for identifying new well locations over the period between the 2004 and 2010 image acquisitions. 


\section{Methods}

The progression of this research follows the diagram outlined in Figure 3. First, preprocessing was performed on the imagery, followed by image classification using objectbased and pixel-based methods. The three research questions were then addressed based upon the derived maps of land cover change produced from the classifications.

\subsection{Preprocessing}

The quarter quadrangle tiles of Greene County were mosaicked using Erdas Imagine 2011 (ERDAS 2011), applying a histogram match of the $300 \mathrm{~m}$ overlap areas for normalization (Fig. 3). Although the majority of the image tiles appear to be matched well with this procedure, some tiles remained noticeably different. Next, the $1 \mathrm{~m}$ imagery was upscaled to coarser spatial resolutions through pixel aggregation to produce 4 additional images at 2, 5, 15, and $30 \mathrm{~m}$ (Fig. 3). Upscaling was applied to eliminate problems associated with using different imagery from each scale, including issues due to differences in sensors, atmospheric conditions, and viewing geometry, as well as the challenge of finding images from different sensors of the same time period (Yang and Merchant 1997). These steps were performed using both the 2004 and 2010 imagery, to produce a total of 10 images to be used in classification and analysis.

Visual comparisons through overlaying the two NAIP images suggested that in places the horizontal error co-registration is approximately $\pm 3 \mathrm{~m}$. Further attempts to improve alignment were not successful in decreasing the error or the root mean squared error (RMSE) and therefore further geometric coregistration was not performed. 


\subsection{Land cover classifications}

A binary classification scheme using only the classes Forest and Non-forest was used to classify the 2004 and 2010 images at each spatial resolution using the three bands common to both datasets (green, red, and near infrared bands). Forest is defined as patches of tree cover exceeding a minimum mapping unit (MMU) of $1800 \mathrm{~m}^{2}$ (the area of two $30 \mathrm{~m}$ pixels). Nonforest is defined as all other land cover classes, including buildings and other developed surfaces, open grasslands, agricultural fields, water, shadow, etc. These class definitions were used for both the 2004 and 2010 images at each of the 5 resolutions.

The per-pixel classification used a maximum likelihood classifier to produce the thematic maps of land cover for both image dates. Due to variation in spectral response within the Nonforested class (e.g. bright concrete versus asphalt), 5-10 training areas were collected for each spectrally distinct sub-class and the sub-classes were only merged after classification. A thematic map was produced for each spatial resolution of the 2004 and 2010 images and then overlaid to produce a final map of land cover change at each of the resolutions. These images were filtered using the Erdas Imagine 2011 "Clump" and "Eliminate" processes to remove patches less than the MMU of $1800 \mathrm{~m}^{2}$ for all types of land cover classes and to replace the land cover value with the same class as the majority of the surrounding pixels.

Object-based classifications were performed using eCognition Developer 8 (Trimble 2011). The first step in object-based image analysis is to segment the image into objects that may then be characterized using textural and spectral properties (Gamanya et al. 2009). A multiresolution segmentation algorithm was used to segment each of the images, with a qualitative iterative analysis used to determine the optimal scale, shape, and compactness segmentation parameters. Scale is an arbitrary value that influences the size of segmented 
objects. Shape values can range between 0 and 0.9 and define the relative weight of polygon shape versus color, or spectral homogeneity (Trimble 2011). Compactness values range between 0 and 1 and determines the balance between smooth and compact edges (Myint 2011). All three spectral bands were used in the segmentation, with the near infrared band weighted twice as much as the green and red bands because the forest class is most distinctive at these wavelengths.

Once suitable image segmentations were produced, rulesets were developed empirically by testing specific rules and thresholds for classifying Forest and Non-forest objects (see Figure 10 in the Appendix for example and explanation of a ruleset). Rules that were used to classify objects include parameters for mean brightness, standard deviation of a single band, mean values of a single band, and a normalized difference vegetation index (NDVI) ratio parameter (Tucker 1979). NDVI is:

$$
N D V I=\frac{\left(R_{\mathrm{NIR}}-R_{\mathrm{red}}\right)}{\left(R_{\mathrm{NIR}}+R_{\mathrm{red}}\right)}
$$

where $R$ is the reflectance and the subscript NIR and red represent the NIR and red bands,

respectively. The same underlying rules were used for each classification although thresholds of the parameters were manually adjusted to produce a qualitatively determined optimal classification for each of the 10 images. Rasterized polygon classifications were exported from eCognition Developer 8 and overlaid to produce the map of change objects. The maps of land cover change were then filtered using the same methods as the pixel-based classifications to eliminate objects smaller than the MMU.

\subsection{Land cover change map accuracy assessment}

Accuracy assessments were performed for the maps of land cover change using a visual interpretation of the $1 \mathrm{~m}$ images as the reference data source. The number of sample points was 
determined using a calculation for a multinomial distribution based on the number of classes (4 change classes), the proportion of the largest class (63\%), and a 95\% confidence level with $7 \%$ precision (Congalton and Green 2009). The sample size was rounded up and 300 randomly generated points were used for accuracy assessment of the thematic maps produced using the per-pixel supervised classification method. The same points were used for each of the 5 maps of land cover change at $1 \mathrm{~m}, 2 \mathrm{~m}, 5 \mathrm{~m}, 15 \mathrm{~m}$, and $30 \mathrm{~m}$ resolutions. Overall, user's, and producer's accuracies were calculated using a confusion matrix.

A commonly used measure of accuracy is the Kappa statistic (Cohen 1960), which accounts for the proportion of the image that could be correctly classified due to random chance. A recent paper by Pontius and Millones (2011), however, points out limitations in the Kappa coefficient and proposes new measures of accuracy-quantity and allocation disagreement. Pontius and Millones (2011) define quantity disagreement as the difference between the reference data and the classified data based upon mismatches of class proportions. Allocation disagreement can be considered the difference between the classified data and reference data due to incorrectly allocated pixels or objects in the classification (Pontius and Millones 2011). Both measures are easily calculated from the accuracy assessment sample points and are included as part of this research.

A review of literature by Rakshit (2011) draws the conclusion that there is no standardized method for accuracy assessment of object-based classifications, and that authors often omit or provide only vague descriptions of methods for accuracy assessment. However, Congalton and Green (2009) have suggested that objects be the sampling units of thematic accuracy assessment for maps produced using object-based classification methods. In my 
research, the unit for the object-oriented accuracy polygons of assessment was the change polygon, defined by the intersection of the two underlying dates (Fig. 4).

The object-based method of accuracy assessment consisted of two parts. First, the points used in the pixel-based accuracy assessment were used in eCognition Developer 8 to extract the objects from both the 2004 and 2010 classifications which contained the randomly selected sample points. These separate sets of objects were then intersected using Environmental Systems Research Institute (ESRI) ArcMap 10 and the intersection of the two objects was used as the polygons for accuracy assessment. The clear majority of the underlying polygon was used as the reference class, following the procedure recommended by Dorren et al. (2003). Accuracy was assessed for each polygon based on visual interpretation and was assigned a corresponding class value based upon a clear majority of the object. Overall accuracy for object-based maps are given as area-weighted accuracies, in which the summed area of correctly classified objects is divided by the total area of all objects used in the assessment.

A comparison of thematic map accuracies of the final change products was performed to investigate how overall accuracy changed with spatial resolution, as well as how accuracy varied between classification methods. Error estimate measures were also calculated using a modified version of an equation used to determine the sample size based on binomial probability theory (Jensen 2005).

$$
E=\sqrt{\frac{Z^{2}(p)(q)}{N}}
$$

where $E$ is the error estimate for a specified sample size $(N)$, accuracy $(p)$, and confidence level $(q=100-p)$ (Fitzpatrick-Lins 1981). The value for $Z$ is 2 in this equation and is from the standard normal deviate of 1.96 for the $95 \%$ two-sided confidence level. Error estimates were calculated to determine statistical differentiation of one overall thematic accuracy from another. 


\subsection{Land cover change of new clearings accuracy assessment}

In addition to investigating how overall accuracy varies with spatial scale and classification method, I also examined how scale and classification method affect accuracy of identification of new clearings within forested areas associated with natural gas development.

The gas well point dataset was used to identify the wells that were not present (forested area) in 2004 and were present (cleared forest) in the 2010 imagery. The ability to assess land cover change using a point dataset poses a problem, since the features of interest, well clearings, have an areal extent. 180 of these well points were randomly selected throughout Greene County and the extent of the well pad clearing was manually digitized for each point. Only the well clearing was included in the polygon that was digitized, and not access roads to the site that were sometimes visible. All polygons included in the accuracy assessment were greater than the MMU of $1800 \mathrm{~m}^{2}$.

The well clearing polygons were then converted to raster files, one for each of the 5 spatial resolutions studied, and the land cover classes mapped in the change analysis within each clearing were summarized using the land cover change maps of both classification methods for each of the respective spatial resolutions. The total area of each class from the sample of 180 clearings was tabulated and the proportion of correctly identified land cover change within each polygon was summarized. Each polygon well clearing was assumed to represent the "Forest-toNon-forest" class and a percentage of correctly identified change was calculated to provide insight into how well each classification method and spatial resolution combination identifies land cover change of well clearings. 


\subsection{Landscape metrics scaling relations}

My third objective was to investigate how landscape metrics change with image spatial

scale. Five selected landscape metrics (Table 1) were computed for both the 2004 and 2010 object-based classifications at each of the 5 spatial resolutions using Patch Analyst (Rempel et al. 2008). Patch Analyst is similar to the popular software FRAGSTATS (McGarigal et al. 2002) but has the benefit of integration with ArcGIS as an extension.

Scaling relations of five class-level landscape metrics (Table 1) were observed across the

five spatial resolutions for comparison with those observed by Wu et al. (2002) and Wu (2004). In these previous studies, the class metrics scaling relations were identified for thematic maps ranging from 30-3 $000 \mathrm{~m}$ spatial resolution. My research focused on finer spatial resolutions, ranging from 1-30 m. Average values of each metric were computed from 30 sample quadrats for both Forest and Non-forest classes of the 2004 and 2010 image dates. This provided four different classes of landscape metric values that were plotted on a scalogram, which is a graph of landscape metric value versus spatial resolution.

\subsection{Temporal change in landscape metrics}

Lastly, I examined whether the pattern of forest cover in the study area, as measured by landscape metrics, changed significantly over the period 2004-2010. A method for sampling the image similar to that of Griffith et al. (2003) was used to impose a grid of $3 \times 3 \mathrm{~km}$ quadrats over Greene County and select 30 stratified random samples, without replacement, for the analysis. The samples were stratified based upon the number of new well clearings within each quadrat which is further discussed below. Subsampling the image is necessary both for statistical 
significance testing requiring a minimum number of samples as well as to avoid software/processing limitations due to file size.

Quadrat samples were analyzed for statistically significant changes in metrics over the 6year period and then split into two categories based upon the number of new wells (cleared between 2004 and 2010) within each quadrat. High-activity samples are defined as quadrats having 13 or more wells per $9 \mathrm{~km}^{2}$ quadrat; 12 quadrats met this threshold, ranging between 1323 wells per quadrat, and 10 of these were randomly selected. The remaining 156 quadrats were considered low-activity areas, containing 12 or fewer wells per quadrat, and 20 of these quadrats were randomly selected.

Patch Analyst was used to compute landscape metrics for each sample for the 2004 and 2010 classifications at all 5 spatial resolutions of the object-based classifications and then tested for significant changes. The Wilcoxon signed ranks test statistic, which is a nonparametric statistical test used to compare two related samples and identify significant differences between the measured pairs (Corder and Foreman 2009), was calculated at each spatial resolution to check for consistency across the spatial resolutions and to identify statistically significant changes in metrics. 


\section{Results}

\subsection{Land cover classification comparison}

The well clearings are apparent in the pixel-based maps at each of the spatial resolutions (Fig. 5). The full extent of each well clearing is not accurately reflected in any of the maps, although the basic shape of each clearing is evident. Also note that differentiation between forest and some non-forest cover types is more accurate at $1-5 \mathrm{~m}$ than at 15 and $30 \mathrm{~m}$. For example, the clearing in the lower right portion of the 2004 and 2010 images (indicated by A in Fig. 5) is identified mostly as "Unchanged Non-forest" (black) at all resolutions of the per-pixel change maps, but the clearing on the far left of the images (B in Fig. 5) is identified as "Forest to Nonforest" (red) at the three finer spatial resolutions, and then is a mix between "Unchanged Nonforest" and "Non-forest to Forest" (chartreuse) in the 15 and $30 \mathrm{~m}$ change maps. The latter class is primarily in areas that were in fact forest in both images and did not change over the time period. This indicates that the areas were misclassified in the 2004 image but were correctly classified in the 2010 image. Visual inspection of the maps of land cover change produced using the per-pixel classification method show slight variation in the classifications as the spatial resolution changes, although the well clearings are identified reasonably well at all spatial resolutions.

The object-based classification method identified a portion of the disturbed forest for each well clearing, although the extent of the clearings is not as clear for some clearings as it was in the supervised classifications (Fig. 5). For example, the well clearing in the upper left portion of the figures ( $\mathrm{C}$ in Fig. 5) shows a new clearing, but the $2 \mathrm{~m}, 5 \mathrm{~m}$, and $15 \mathrm{~m}$ maps of land cover change have "Unchanged Forest" as the land cover class for portions of this clearing. Although less common than in the pixel-based classification maps, the presence of the "Non-forest to 
Forest" class in all five classifications is an error within the classifications, as none of these areas were reforested within the 6 years between images. As one might expect, minor land cover changes such as access roads to wells are better identified at finer resolutions between $1 \mathrm{~m}$ and 5 $\mathrm{m}$, although none of the maps fully and accurately identify the entire extent of these smaller changes to the forest.

\subsection{Land cover change map accuracy assessment comparison}

The most accurate pixel-based map of land cover change produced was the $5 \mathrm{~m}$ map at 81.6\% (Table 2 (e), Fig. 6), and the $1 \mathrm{~m}$ and $2 \mathrm{~m}$ maps (Table 2 (a) and (c), respectively) having nearly the same accuracy (81.3\%), and the two coarser resolution maps having accuracies slightly lower.

For the object-based series of maps, the most accurate classification method was the $1 \mathrm{~m}$ map (Table 2 (b), Fig. 6) at $87.1 \%$ and the $5 \mathrm{~m}$ map (Table 2 (f), Fig. 6) at $82.3 \%$ had the second most accurate classification. Again, the $15 \mathrm{~m}$ and $30 \mathrm{~m}$ object-based change maps (Table 2 (h) and (j), respectively) had lower accuracies $(74.7 \%$ and $76.0 \%$, respectively) than the finer resolution classifications. The $1 \mathrm{~m}$ object-based classification was the most accurate of all the classification method/spatial resolution combinations.

Although the results show that accuracy is higher at some spatial resolutions, the objectbased accuracy measures are not statistically distinguishable from the pixel-based accuracy measures for any spatial resolution. The $1 \mathrm{~m}$ object-based classification is the only spatial resolution/classification method that produced a map statistically more accurate than any other. However, the $1 \mathrm{~m}$ map is only better than the maps produced at 15 and $30 \mathrm{~m}$ spatial resolutions and all others are not differentiable by scale or method. 
The quantity disagreement values for both classification methods range from 0.07-0.21, indicating that approximately $7-21 \%$ of the classified images are classified as the incorrect class (Table 2). Allocation disagreement is very similar for the object-based and pixel-based maps, ranging between 0.06-0.12 indicating that for most classifications - given the proportions of each

class in the respective maps-pixels/objects were spatially allocated accurately approximately $90 \%$ of the time. Therefore, these two measures of accuracy imply that in general, the quantity of pixels apportioned to each class was a source of error more often than the spatial allocation of classes within the classifications.

\subsection{Land cover change of new clearings accuracy assessment}

The object-based classification most accurately identified this type of land cover change at $1 \mathrm{~m}$ resolution with an overall trend of decreasing accuracy as pixel size increased (Fig. 7). In comparison, the pixel-based classification most accurately shows land cover change associated with well clearings at $30 \mathrm{~m}$ and the overall pattern is decreasing accuracy as the resolution becomes finer. In both classification methods, the $5 \mathrm{~m}$ maps are an exception to the trend with accuracies slightly higher than expected given the overall trends. The opposite is true of pixelbased classifications - the accuracy increases with coarser resolutions at least up to $30 \mathrm{~m}$. At even coarser spatial resolutions the accuracies of the pixel-based classification would likely decrease as the pixel size started approaching the scale of the well clearings.

\subsection{Landscape metrics scaling relations}

Scalograms reveal that the number of patches metric (Fig. 8 (a)) declines as spatial resolution becomes coarser for all four classes. Edge density (Fig. 8 (b)) was found to have the 
same scaling relations, decreasing from approximately $450 \mathrm{~m}$ of edge per hectare to less than 100 $\mathrm{m}$ of edge per hectare as the spatial resolution coarsens from 1 to $30 \mathrm{~m}$. The mean patch size (Fig. 8 (c)) metric shows fairly consistent scaling relations for all classes although the metrics for the forest classes increase more sharply at $15 \mathrm{~m}$ and $30 \mathrm{~m}$ than the non-forest classes. Mean shape index (Fig. 8 (d)) shows a relatively consistent, decreasing power function with decreasing spatial resolution. The last metric, percent of landscape (Fig. 8 (e)) seems insensitive to scale, changing little as spatial resolution increases.

\subsection{Temporal change in landscape metrics}

The second question relating to landscape metrics addressed here is whether or not there are statistically significant changes in forested areas within Greene County between 2004 and 2010 due to natural gas development (Tables 3, 4, and 5). When all 30 sample quadrats are included in analysis, some interesting patterns emerge (Table 3). Edge density (ED), which is typically associated with increase fragmentation, increased significantly between 2004 and 2010 for the $15 \mathrm{~m}$ and $30 \mathrm{~m}$ classifications but not at fine resolutions. However, patch size and the proportion of forested land within the study area were observed to have increased significantly, at least at some of the finer resolutions. The mean shape index (MSI) shows a significant decrease at $2 \mathrm{~m}$ resolution but a significant increase at $30 \mathrm{~m}$ resolution.

Results of the low-activity signed ranks test indicate that within these quadrats with relatively few wells, forested areas appear to have increased in patch size at $2 \mathrm{~m}$, and the proportion of forest in the total landscape has increased at both 2 and $5 \mathrm{~m}$ resolutions (Table 4). Change in mean patch size (MPS) is the most consistently significant of all of the metrics, at least between 2 and $15 \mathrm{~m}$, and change in edge density (ED) was not significant at any of the 
spatial resolutions for low-activity samples. The mean shape index (MSI) data indicate a significant increase in the metric at 2 and $30 \mathrm{~m}$ resolutions suggesting more complex shapes in 2010, whereas at $5 \mathrm{~m}$ the MSI metric significantly decreased over the 6-year period. Table 4 indicates that classifications at $2 \mathrm{~m}$ and $5 \mathrm{~m}$ scales show an increase in the proportion of forest in the low-activity samples of Greene County.

Table 5 shows the results of the Wilcoxon signed ranks test for changes in landscape metrics for the 10 high-activity quadrat samples. The only landscape metric that changed significantly for these samples was Edge Density (ED) which significantly increased for the 1, 5, and $30 \mathrm{~m}$ resolutions. Edge density was expected to increase for high-activity areas since roads and clearings cutting into forested areas would increase the perimeter-to-area ratio. Other metrics, such as mean patch size (MPS) and number of patches (\#PAT), were not expected to change significantly as a result of natural gas development, primarily because the clearings are not greatly reducing the size of forest patches or dividing them into separate patches. Most notable is the fact that classifications produced at different spatial resolutions produce different landscape metrics values. For example, changes in landscape metrics found to be significant at one spatial resolution are not necessarily significant at other spatial resolutions.

Maps of new well clearings (wells within forested areas cleared between 2004 and 2010) also provide insight into understanding how metrics changed over time for the high and low activity quadrats. The metrics for the $5 \mathrm{~m}$ classifications are shown in Figure 9 because they are a good example of the associations observed. Change over the 6-year period in the number of patches (\#PAT) (Fig. 9 (a)) does not seem to show any distinctive pattern related to new well activity. Change in the edge density metric (ED) (Fig. 9 (b)) generally increased in the highactivity samples and decreased in the low-activity areas. For the most part, mean patch size 
(MPS) (Fig. 9 (c)) decreased in high-activity areas and increased in areas with fewer well clearings although there are a couple exceptions. Mean shape index (MSI) (Fig. 9 (d)) shows no strong relationship between well density and metric change and neither does the percent of landscape metric (PLAND) (Fig. 9 (e)). In summary, the results differ in high-activity vs. lowactivity areas, with only some landscape metrics, such as edge density, appearing to be connected with landscape changes associated with gas development. 


\section{Discussion}

\subsection{Comparison of classification methods}

Multiple maps of land cover change between 2004 and 2010 in Greene County, Pennsylvania were produced in this research, and two classification methods - pixel-based and object-based-were compared across five spatial resolutions. The most common classification errors for both methods came from similarities between digital number (DN) values of forest pixels/objects and other vegetated pixels/objects. This lead to the misclassification of some agricultural fields as forest, because brightly illuminated forest had similar reflectance to other vegetation. Classification error of this type explains some of the land cover change classified as "Non-forest to Forest".

The accuracy assessment indicated that the two methods did not differ significantly from one another at any of the observed spatial resolutions (Fig. 6). The $1 \mathrm{~m}$ object-based classification was, however, statistically different from the $15 \mathrm{~m}$ and $30 \mathrm{~m}$ maps of both methods. This similarity in classification accuracy may be the result of the post-classification filtering process which eliminated some of the salt-and-pepper effect common to pixel-based classifications. On the other hand, the filtering specifications may have been too aggressive in some instances and actually decreased classification accuracy. Based on the overall accuracies of both classification methods, it seems that either classification method for $1 \mathrm{~m}$ spatial resolution imagery would be most suitable for assessing land cover change if a post-classification filtering process is performed. However, due to cost and revisit limitations of some data sources, other scales and data sources may prove more viable in future applications.

The use of NAIP imagery for evaluating land cover change poses several distinctive challenges that may be overcome using other data sources. Mosaicking quarter quadrangle tiles 
collected over an entire growing season leads to differences in DN values across multiple image tiles as plant phenology, time of day, and illumination vary between image acquisition times. Histogram matching of overlap areas helped normalize some of these differences but some image tiles were still noticeably different. Also, although shadows tend to be consistent at least within individual quarter quadrangle tiles, they are challenging to classify correctly, especially for within-forest shadows that may be misclassified as forest clearings. The ideal would be to use satellite data that covers the entire study area in one image. This would eliminate problems of within scene variations in phenology and illumination. It must also be noted that the average size of a natural gas well clearing is approximately $60 \times 60 \mathrm{~m}$, so although $30 \mathrm{~m}$ imagery (such as Landsat) could be used to monitor this type of land cover change, it is unlikely that imagery coarser than $30 \mathrm{~m}$ spatial resolution would prove useful for observing this process. The temporal resolution of the sensor also factors into the ability to accurately classify and assess land cover change, because gas well clearings could potentially be cleared and re-vegetated with grass or shrubs in a relatively short period of time, making clearings more spectrally similar to the surrounding forest. Therefore, a satellite-borne data source with a spatial resolution finer than 30 m (such as NASA's ASTER or any one of the commercial high resolution sensors) with the ability to acquire images at yearly intervals would be most effective for monitoring land cover change associated with natural gas development.

\subsection{Accuracy of clearing identification}

In examining the accuracy of classification of existing clearings, the $1 \mathrm{~m}$ object-based classification was found to be the most accurate, although the overall accuracy of the map does not differ statistically from those of the $2 \mathrm{~m}$ and $5 \mathrm{~m}$ maps. Based on these general patterns, it 
supports observations in the literature that object-based classifications are most accurate with fine resolution imagery, but are less suitable at coarser scales. In contrast, the best resolution for mapping clearings for the pixel-based classifications was the $30 \mathrm{~m}$ map (Fig. 7). It is notable that for the pixel-based method, the proportion of correctly identified land cleared for wells increased

as spatial resolution became coarser. Spatial coregistration of images may also contribute to lower accuracy of fine spatial resolution pixel-based classifications. Although classifications produced at 15 or $30 \mathrm{~m}$ using a pixel-based classification method were the most accurate for identifying new well clearings, they are less suitable for identifying fine-scale habitat fragmentation. This observation is consistent with Giner and Rogan (in press), who suggest that coarser resolution imagery, such as Landsat ETM, is suitable for mapping large contiguous forest patches but is less suitable for capturing more complex patterns.

\subsection{Landscape metrics scaling relations}

The five landscape metrics that were calculated for each of the five spatial resolutions tend to confirm and extend to finer spatial resolutions the scaling patterns observed by Wu et al. (2002) and $\mathrm{Wu}(2004)$ (see also Table 1). Similar to Wu et al. (2002), the number of patches and edge density were found to have a predictable, decreasing power law function. Wu et al. (2002) found that the mean patch size showed an increasing power law function which was also similar to results in this paper. One metric that appears to change in a more consistent fashion as spatial scale changed than was found by Wu et al. (2002) is the mean shape index metric, which appears to have a consistent decreasing power function (Fig. 8).

A follow-up paper published by Wu (2004) grouped metrics into "consistent, robust", "consistent, less robust", and "inconsistent" scaling relation categories. Again, the current 
research produced similar scaling relations, with number of patches and edge density having consistent and robust relationship, mean patch size having consistent but less robust scaling relations, and percent of landscape having inconsistent scaling relations. However, it appears that mean shape index would fall under the "consistent, robust" category in this research rather than the "inconsistent" category characterized by Wu (2004). The difference in scaling relations may be due to the types of land cover examined or the finer spatial resolutions studied. Another explanation for the differences in scaling relations is the fact that Wu et al. (2002) calculated landscape metrics at the landscape-level and not the class-level which may account for the different patterns. Scaling relations are important to understand when using landscape metrics to characterize ecological patterns since metrics calculated at one spatial resolution may not accurately reflect a process operating at a different scale (Wiens 1989).

\subsection{Temporal change in landscape metrics}

The final aspect of this research focused on changes in landscape metrics between 2004 and 2010 for the object-based classifications produced at each spatial resolution. Two of the metrics - edge density (ED) and mean shape index (MSI) were expected to increase as a result of natural gas development in sample quadrats that showed a high densities $(>12)$ of new wells cleared between 2004 and 2010. The other three metrics - mean patch size (MPS), number of patches (\#PAT) and percent of landscape (sample) (PLAND) were not expected to change significantly in these high-activity areas. These outcomes were expected because natural gas development does not require large areas of land to be cleared, but rather forest is fragmented by cutting roads to clearings internal to forest patches. 
For the most part, my results show that natural gas development is indeed leading to increased forest fragmentation in high-activity areas when compared to areas where there are fewer new wells. Interestingly, however, no metric besides edge density (ED) changed significantly at any spatial resolution for high-activity samples. Likewise, the significant changes in low-activity samples seem to trend toward increased forested area and increased patch sizes. This trend may be due to many contributing processes, such as agricultural abandonment, which is the process of natural succession upon previously farmed land. My results also suggest that classification error, as well as spatial resolution, can have profound impacts on metrics analyses and can be chosen specifically for a desired outcome. For instance, changes due to natural gas development that occur in concentrated areas may not be apparent in summary statistics generated from a study area of large geographic extent. Additionally, the $3 \mathrm{~km}^{2}$ quadrats used in this study are potentially too small for $30 \mathrm{~m}$ thematic data, encompassing squares of only 100 pixels per side. The size was kept constant between the 5 spatial resolutions to maintain identical samples in terms of geographic extent for comparing scaling relations, but edge effects may have impacted results at the coarser spatial resolution. Therefore, any type of landscape metric analysis must be reviewed with caution in the land management decision-making process.

Edge density was the only metric that showed a significant increase in fragmentation over the six-year period (Table 5). Increased edge density reduces continuous forested areas important for some species, as well as opens new routes to invasive species to infiltrate natural ecosystems (Soeder 2010). This is important to note for land managers and wildlife biologists because natural gas development is continuing in this area, and thus edge density is likely to increase. The consequence of increased edge density in this area is likely to differ by the affected species. For example, access roads may pose more of a threat to smaller animal species and plant species 
than to larger animals such as the whitetail deer. Thus, although this research gives an indication of which metrics may be changing, further research is needed to explain the ecological significance.

It is notable that the patterns of changes in landscape metrics for the county as a whole were not consistent with those observed when the county was stratified into high-activity and low-activity areas. This suggests that summary landscape metrics over large areas can obscure important, but contradictory patterns, in different regions of the study area. Although the use of landscape metrics within the context of this study focused on evaluating whether natural gas development is significantly altering the landscape, it is difficult to isolate changes in metrics due solely to this type of activity from other types of development. However, the use of highactivity and low-activity samples does show that there tends to be increased fragmentation in high-activity areas as would be expected.

This research provides an overall assessment of how the forested areas of Greene County have changed over the past six years as a result of natural gas development as well as other resource extraction industries. Significant change was only evident for some landscape metrics and not others. The overall changes in metrics might not be as important as the spatial arrangement of these changes upon the landscape in the context of fine-scale habitat studies. Therefore, more focus on fragmentation related to natural gas development at a scale finer than the county level is necessary, because changes at the broader scale may be small, but at the same time the change at the local level (as shown in Fig. 9) may be complex and significant. 


\section{Conclusions and future research}

The classifications produced for this study were the result of a pixel-based maximum likelihood supervised classification and an object-based membership function classifier. The two methods produced maps with an accuracy that varied between 74.7-87.1\%. However, the $1 \mathrm{~m}$ object-based classification was the only map that was statistically more accurate than any other map. Thus, as scales become coarser than $1 \mathrm{~m}$, there was no difference between the classification methods. My research has shown NAIP imagery to be a useful, low-cost data source, although several limitations of the data provide ample justification for testing classification methods using alternate imagery sources. In particular, radiometric normalization between images acquired at different times of day and even different months is a challenge.

As the spatial resolution of object-based classifications coarsens, the accuracy of correctly identified well clearings decreased, which is what was expected based on previous studies. In contrast, pixel-based accuracy increased as spatial resolution coarsened. Thus, the two classification methods indicate higher accuracy at opposite ends of the analyzed spatial resolutions. Perhaps more importantly for the specific context of gas wells, the $1 \mathrm{~m}$ object-based classification was significantly more accurate overall than the $30 \mathrm{~m}$ classification, but the $30 \mathrm{~m}$ pixel-based classification was slightly more accurate when identifying well clearing land cover change.

Although complete automation for identifying gas well clearings is not yet possible, object-based rulesets provide a unique opportunity for incorporating not only shape, texture, and spectral properties, but also the relationships with surrounding objects. Image segmentation parameters affect the classification accuracy, and so care must be taken to develop the most suitable segmentation settings possible (Clinton et al. 2010). As of this writing, there are no 
standardized methods for choosing optimal segmentation scales and parameters (Myint et al. 2011), although Kim et al. (2009) suggest the use of autocorrelation for selecting the optimal scale parameters. Improvements in both segmentation parameters and ruleset development will greatly advance object-based methods for mapping the extent of well clearings and monitoring this process over a broader geographic scale. However, constraints regarding file size and object segmentation software limitations hinder object-based classification of large (geographic) extents of high-resolution imagery. Therefore, pixel-based classification methods may still be most suitable for efficient classification, with little compromise in accuracy.

Although my research used landscape metrics to investigate scaling relations and to characterize changes in forested lands within the study area, this is only a start to assessing the potential impacts of natural gas development on Appalachian habitats. Scaling relations and statistically significant changes provide a baseline for further investigation into habitat fragmentation and ecological impacts of natural gas development. At finer geographic extents (smaller than the county level), natural gas development, and associated human activities, has the potential to significantly alter natural ecosystems. 


\section{References}

ARZANDEH, S. and WANG, J., 2003, Monitoring the change of Phragmites distribution using satellite data, Canadian Journal of Remote Sensing, 29, pp. 24-35.

BENSON, B.J. and MACKENZIE, M.D., 1995, Effects of sensor spatial resolution on landscape structure parameters. Landscape Ecology, 10, pp. 113-120.

BETTS, M.G., FRANKLIN, S.E. and TAYLOR, R.G., 2003, Interpretation of landscape pattern and habitat change for local indicator species using satellite imagery and geographic information system data in New Brunswick, Canada. Canadian Journal of Forest Research, 33, pp. 1821-1831.

BLASCHKE, T., 2010, Object based image analysis for remote sensing. ISPRS Journal of Photogrammetry \& Remote Sensing 65, pp. 2-16.

CLINTON, N., HOLT, A., SCARBOROUGH, J., YAN, L. and GONG, P., 2010, Accuracy assessment measures for object-based image segmentation goodness. Photogrammetric Engineering and Remote Sensing, 76, pp. 289-299.

COHEN, J., 1960, A coefficient of agreement for nominal scales. Educational \&Psychological Measurement, 20, pp. 37-46.

CONGALTON, R.G. and GREEN, K. (Eds.), 2009, Assessing the Accuracy of Remotely Sensed Data: Principles and Practices. $2^{\text {nd }}$ ed. (Boca Raton, FL: CRC Press). 183p.

CORDER, G.W. and FOREMAN, D.I., 2009, Nonparametric Statistics for Non-Statisticians, pp. 38-56 (Hoboken, NJ: John Wiley \& Sons, Inc.).

CRACKNELL, A.P., 1998, Synergy in remote sensing-what is in a pixel? International Journal of Remote Sensing, 19, pp. 2025-2047.

DAI, X. and KHORRAM, S., 1998, The effect of image misregistration on the accuracy of remotely sensed change detection. IEEE Transactions on Geoscience \& Remote Sensing, 36, pp. 1566-1577.

DORREN, L.K.A., MAIER, B. and SEIJMONSBERGEN, A.C., 2003, Improved Landsat-based forest mapping in steep mountainous terrain using object-based classification. Forest Ecology \& Management, 183, pp. 31-46.

ERDAS, 2011, Erdas Imagine 2011 User Manual (Georgia, USA: Applied Analysis Inc.).

ESRI, 2010, ArcMap 10 User Manual (Redlands, USA: Environment Research Institute).

FERRAZ, S.F. B., CAPÃO, L.M.S.A.C. and VETTORAZZI, C.A., 2006, Temporal scale and spatial resolution effects on Amazon forest fragmentation assessment in Rondônia. International Journal of Remote Sensing, 27, pp. 459-472. 
FITZPATRICK-LINS, K., 1981, Comparison of sampling procedures and data analysis for a land-use and land-cover map. Photogrammetric Engineering \& Remote Sensing, 47, pp. 343-351.

FRANKLIN, S. E., LAVIGNE, M.B., WULDER, M.A. and STENHOUSE, G.B., 2002, Change detection and landscape structure mapping using remote sensing. The Forestry Chronicle, 78, pp. 618-625.

GAMANYA, R., DE MAEYER, P. and DE DAPPER, M., 2009, Object-oriented change detection for the city of Harare, Zimbabwe. Expert Systems with Applications, 36, pp. 571-588.

GINER, N. and ROGAN, J., (in press), A comparison of Landsat ETM+ and high-resolution aerial orthophotos to map urban/suburban forest cover in Massachusetts, USA. Remote Sensing Letters.

GRIFFITH, J.A., STEHMAN, S.V. and LOVELAND, T.R., 2003, Landscape trends in MidAtlantic and Southeastern United States Ecoregions. Environmental Management, 32, pp. 572-588.

HAY, G. J., CASTILLA, G., WULDER, M.A. and RUIZ, J.R., 2005, An automated object-based approach for the multiscale image segmentation of forest scenes. International Journal of Applied Earth Observation \& Geoinformation, 7, pp. 339-359.

HENGL, T., 2006, Finding the right pixel size. Computers \& Geosciences, 32, pp. 1283-1298.

JENSEN, J. R., 2005, Introductory Digital Image Processing: A Remote Sensing Perspective, $3^{\text {rd }}$ ed., (Upper Saddle River: Prentice-Hall). 526 p.

KARGBO, D.M., WILHELM, R.G. and CAMPBELL, D.J., 2010, Natural gas plays in the Marcellus Shale: Challenges and potential opportunities. Environmental Science \& Technology, 44, pp. 5679-5684.

KIM, M., MADDEN, M. and WARNER, T.A., 2009, Forest type mapping using object-specific testure measures from multispectral IKONOS imagery: segmentation quality and image classification issues. Photogrammetric Engineering \& Remote Sensing, 75, pp. 819-829.

KUPFER, J. (in press), Landscape ecology and biogeography: Rethinking landscape metrics in a post-FRAGSTATS landscape. Progress in Physical Geography.

LAUSCH, A. and HERZOG, F., 2002, Applicability of landscape metrics for the monitoring of change: issues of scale, resolution, and interpretability. Ecological Indicators, 2, pp. 3-15.

LECHNER, A.M., STEIN, A., JONES, S.D. and FERWERDA J.G., 2009, Remote sensing of small linear features: Quantifying the effects of patch size and length, grid position and detectability on land cover mapping. Remote Sensing of Environment, 113, pp. 21942204. 
LU, D. and WENG, Q., 2007, A survey of image classification methods and techniques for improving classification performance. International Journal of Remote Sensing, 28, pp. 823-870.

MCGARIGAL, K., CUSHMAN, S.A., NEEL, M.C. and ENE, E., 2002, FRAGSTATS: Spatial Pattern Analysis Program for Categorical Maps. Computer software program produced by the authors at the University of Massachusetts, Amherst. Available online at: http://www.umass.edu/landeco/research/fragstats/fragstats.html (accessed 07 July 2011).

MYINT, S.W., GOBER, P., BRAZEL, A., GROSSMAN-CLARKE, S. and WENG, Q., 2011, Per-pixel vs. object-based classification of urban land cover extraction using high spatial resolution imagery. Remote Sensing of Environment, 115, pp. 1145-1161.

NEWMAN, M.E., MCLAREN, K.P. and WILSON, B.S., 2011, Comparing the effects of classification techniques on landscape-level assessments: pixel-based versus object-based classification. International Journal of Remote Sensing, 32, pp. 4055-4073.

PALMER, M.A., BERNHARDT, E.S., SCHLESINGER, W.H., ESHLEMAN, K.N., FOUFOULA-GEORGIOU, E., HENDRYX, M.S., LEMLY, A.D., LIKENS, G.E., LOUCKS, O.L., POWER, M.E., WHITE, P.S. and WILCOCK, P.R., 2010, Mountaintop mining consequences. Science, 327, pp. 148-149.

PONTIUS JR., R.G. and MILLONES, M., 2011, Death to Kappa: birth of quantity disagreement and allocation disagreement for accuracy assessment. International Journal of Remote Sensing, 32, pp. 4407-4429.

RAKSHIT, R., 2011, A survey of accuracy measures in object-based image analysis maps. $\mathrm{PhD}$ thesis, Clark University, MA

REMPEL, R.S., CARR, A.P. and KAUKINEN, D., 2008, Patch Grid extension for ArcMap: Version 4.2. Available online at: http://flash.lakeheadu.ca/ rrempel/patch/index.html (accessed 15 July 2011).

RENNER, R., 2008, What lies beneath. Environmental Science \& Technology, 42, pp. 7547.

ROBBINS, C.S., DAWSON, D.K. and DOWELL, B.A., 1989, Habitat area requirements of breeding forest birds of the Middle Atlantic States. Wildlife Monographs, 103, pp. 3-34.

RUTCHEY, K. and VILCHECK, L., 1994, Development of an Everglades vegetation map using a SPOT image and the global positioning system. Photogrammetric Engineering \& Remote Sensing, 60, pp. 767-775.

SHAO, G. and WU, J., 2008, On the accuracy of landscape pattern analysis using remote sensing data. Landscape Ecology, 23, pp. 505-511.

SIMMONS, J. A., CURRIE, W.S., ESHLEMAN, K.N., KUERS, K., MONTELEONE, S., NEGLEY, T.L., B.R. POHLAD, B.R. and THOMAS, C.L., 2008, Forest to reclaimed mine land use change leads to altered ecosystem structure and function. Ecological Applications, 18, pp. 104-118. 
SOEDER, D.J., 2010, The Marcellus Shale: Resources and Reservations. EOS, 91, pp. 277-288.

SOUTHWORTH, J., NAGENDRA H. and TUCKER, C., 2002, Fragmentation of a Landscape: incorporating landscape metrics into satellite analyses of land-cover change. Landscape Research, 27, pp. 253-269.

STEHMAN, S.V. and FOODY, G.M., 2009, Accuracy assessment. In The SAGE handbook of remote sensing, T.A. Warner, M.D. Nellis, and G.M. Foody (Eds.), pp. 297-309 (Thousand Oaks, CA: SAGE Publications, Inc.).

TOWNSEND, P. A., HELMERS, D.P., KINGDON, C.C., MCNEIL, B.E., DE BEURS, K.M. and ESHLEMAN, K.N., 2009, Changes in the extent of surface mining and reclamation in the Central Appalachians detected using a 1976-2006 Landsat time series. Remote Sensing of Environment, 113, pp. 62-72.

TRIMBLE, 2011, eCognition Developer 8.64.1 User Guide (Munich, Germany: Trimble Germany).

TUCKER, C. J., 1979, Red and photographic infrared linear combinations for monitoring vegetation. Remote Sensing of Environment, 8, pp. 127-150.

UNITED STATES CENSUS BUREAU, 2000, Census 2000 Decennial Census Data. Available online at: http://factfinder.census.gov/home/saff/main.html?_lang=en (accessed 12 May 2011).

WARNER, T.A., ALMUTAIRI, A. and LEE, J.Y., 2009, Remote sensing of land cover change. In The SAGE handbook of remote sensing, T.A. Warner, M.D. Nellis, and G.M. Foody (Eds.), pp. 459-472 (Thousand Oaks, CA: SAGE Publications, Inc.).

WEAKLAND, C.A. and WOOD, P.B., 2005, Cerulean Warbler (Dendroica cerulea) microhabitat and landscape-level habitat characteristics in southern West Virginia. AUK, 122, pp. 497-508.

WIENS, J.A., 1989, Spatial scaling in ecology. Functional Ecology, 3, pp. 385-397.

WILCOX, B.A. and MURPHY, D.D., 1985, The effects of fragmentation on extinction. The American Naturalist, 125, pp. 879-887.

WU, J., SHEN, W., SUN, W. and TUELLER P.T., 2002, Empirical patterns of the effects of changing scale on landscape metrics. Landscape Ecology, 17, pp. 761-782.

WU, J., 2004, Effects of changing scale on landscape pattern analysis: scaling relations. Landscape Ecology, 19, pp. 125-138.

YANG, W. and MERCHANT, J.W., 1997, Impacts of upscaling techniques on land cover representation in Nebraska, U.S.A.. Geocarta International, 12, pp. 27-39. 


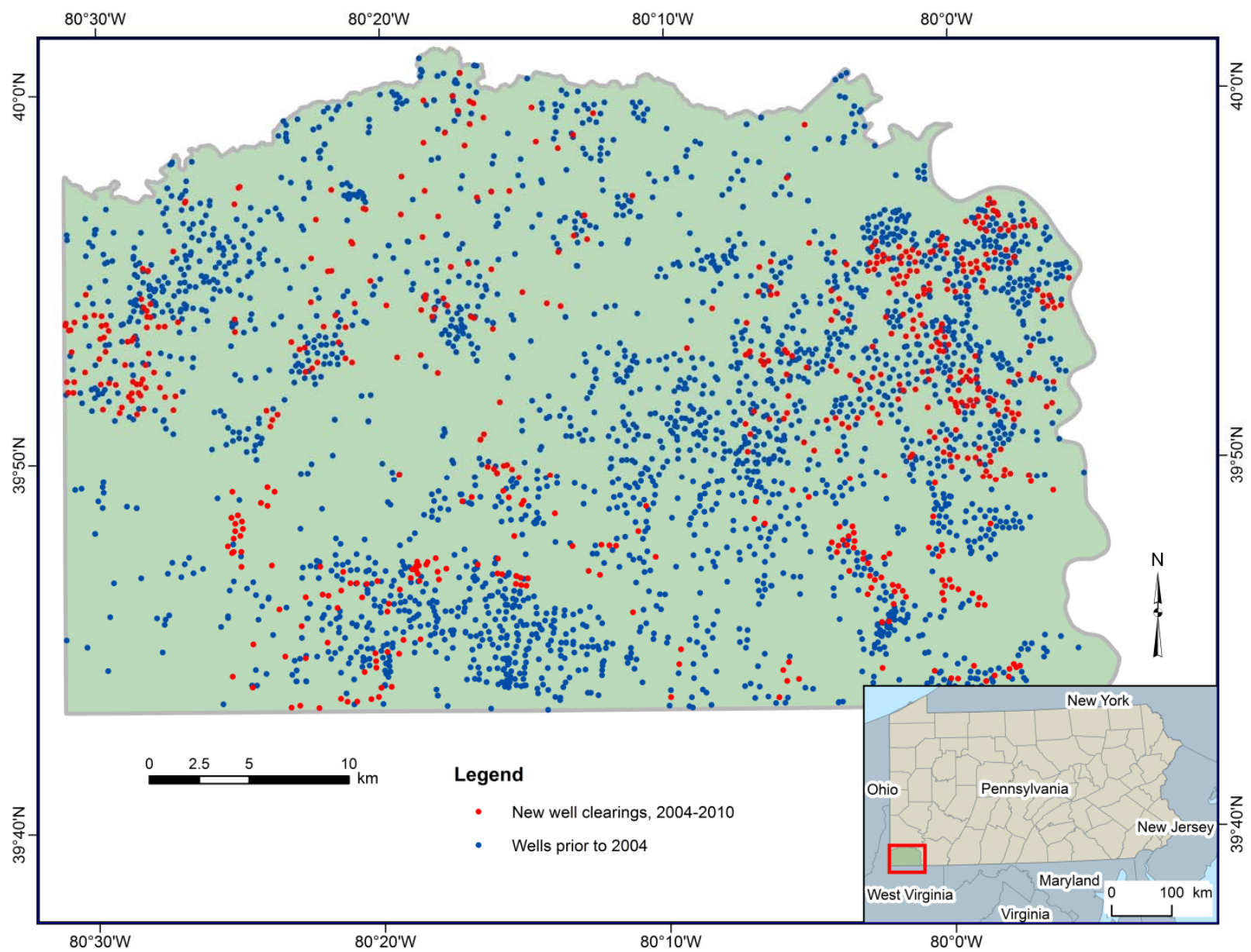

Figure 1. Map of study area showing active oil and gas well permit locations in Greene County, Pennsylvania. Inset map shows Greene County's location in relation to Pennsylvania and surrounding states. 

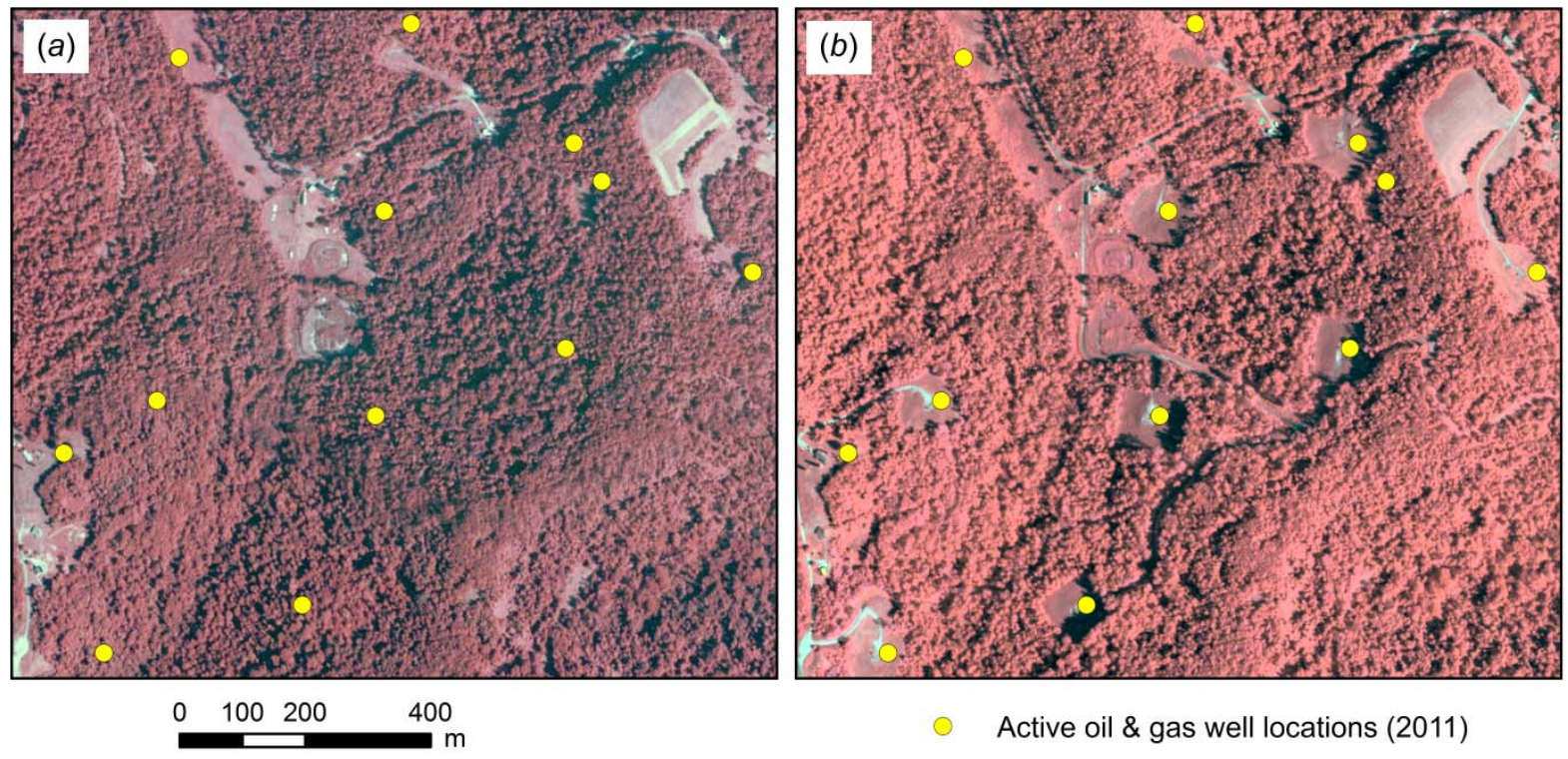

Figure 2. Standard false color infrared National Agricultural Imagery Program (NAIP) images of well locations in forested area near Jefferson, PA (a) 2004 and (b) 2010. Notice increased fragmentation following the placement of well clearings in the 2010 imagery.

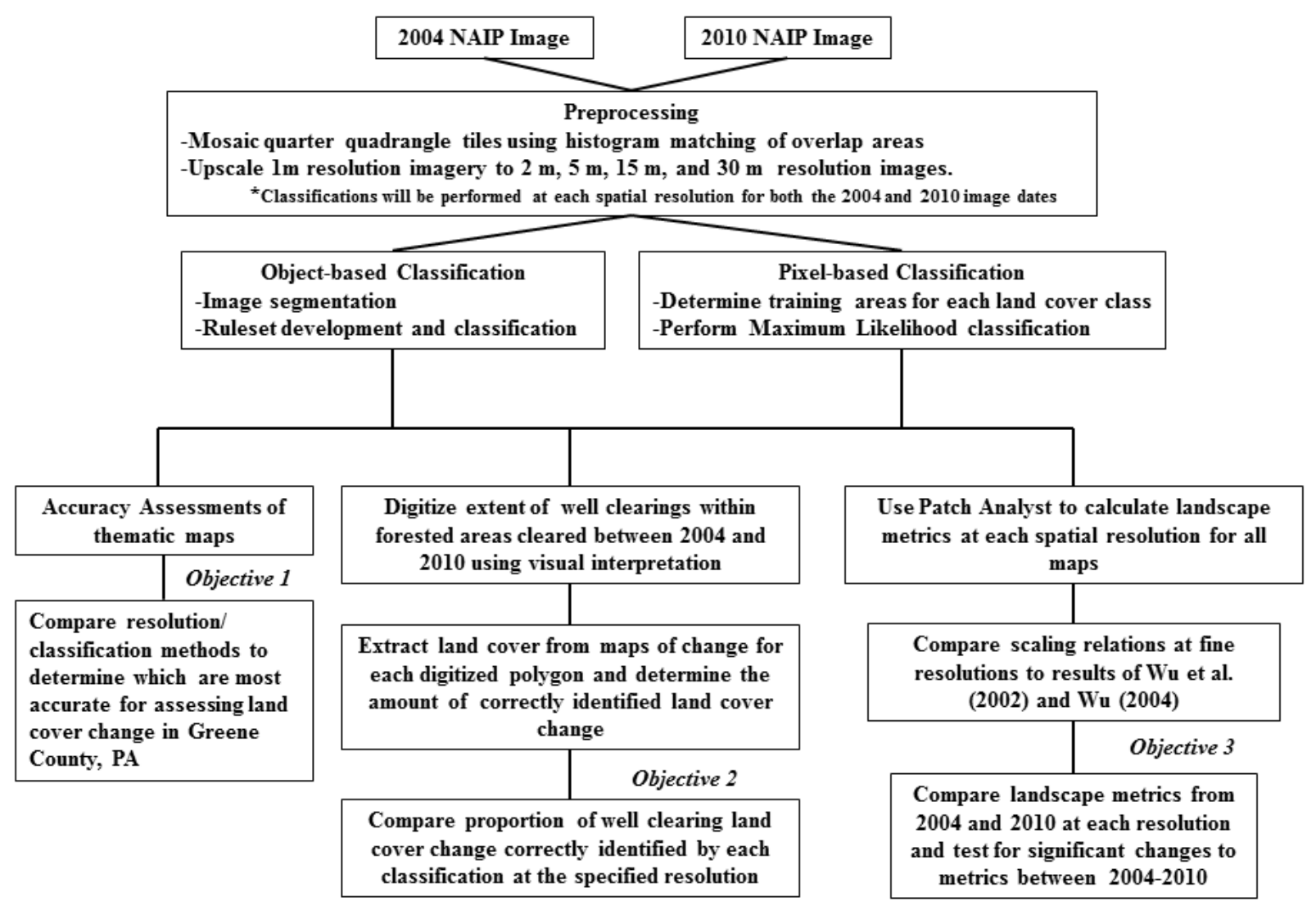

Figure 3. Research flow chart showing main steps in methods and analysis 


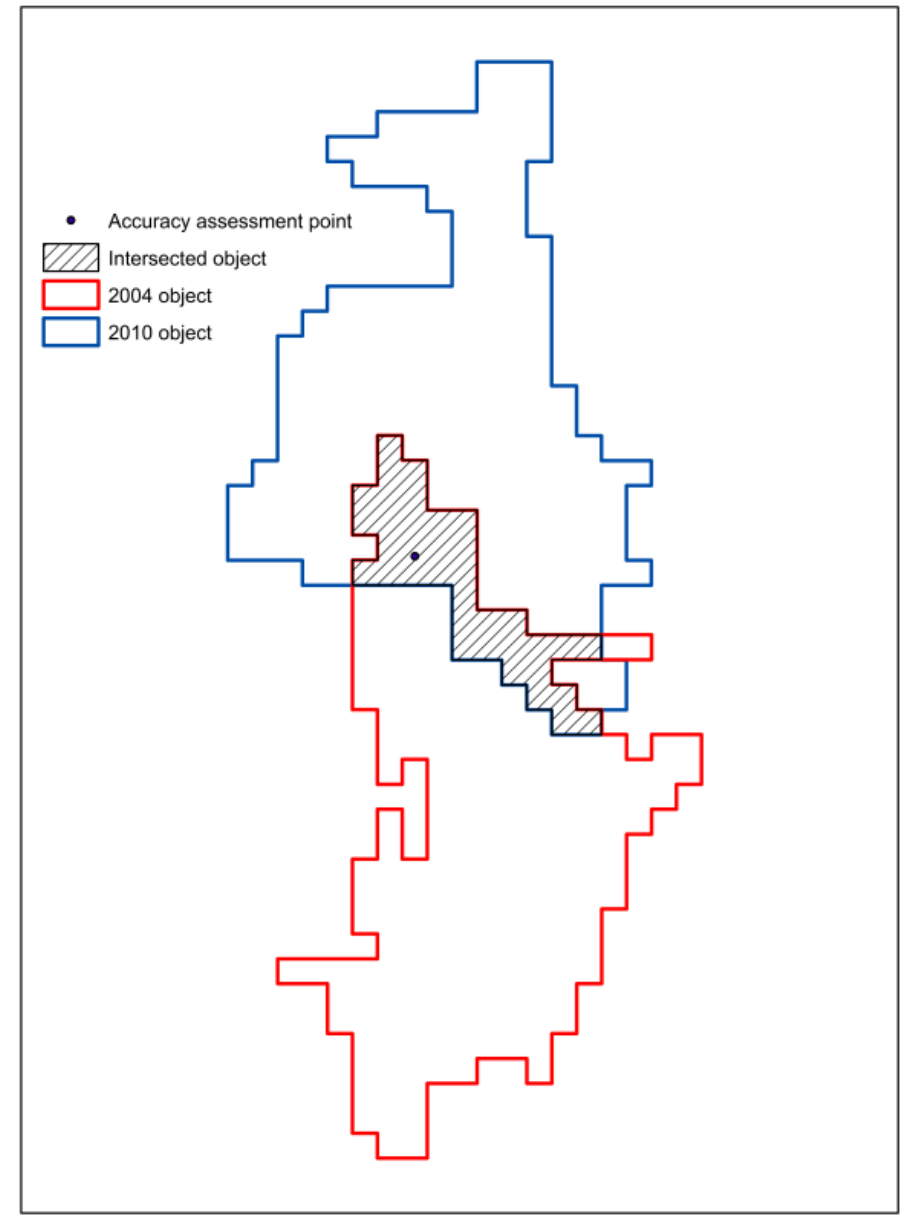

Figure 4. Example of object-based accuracy assessment polygon. 


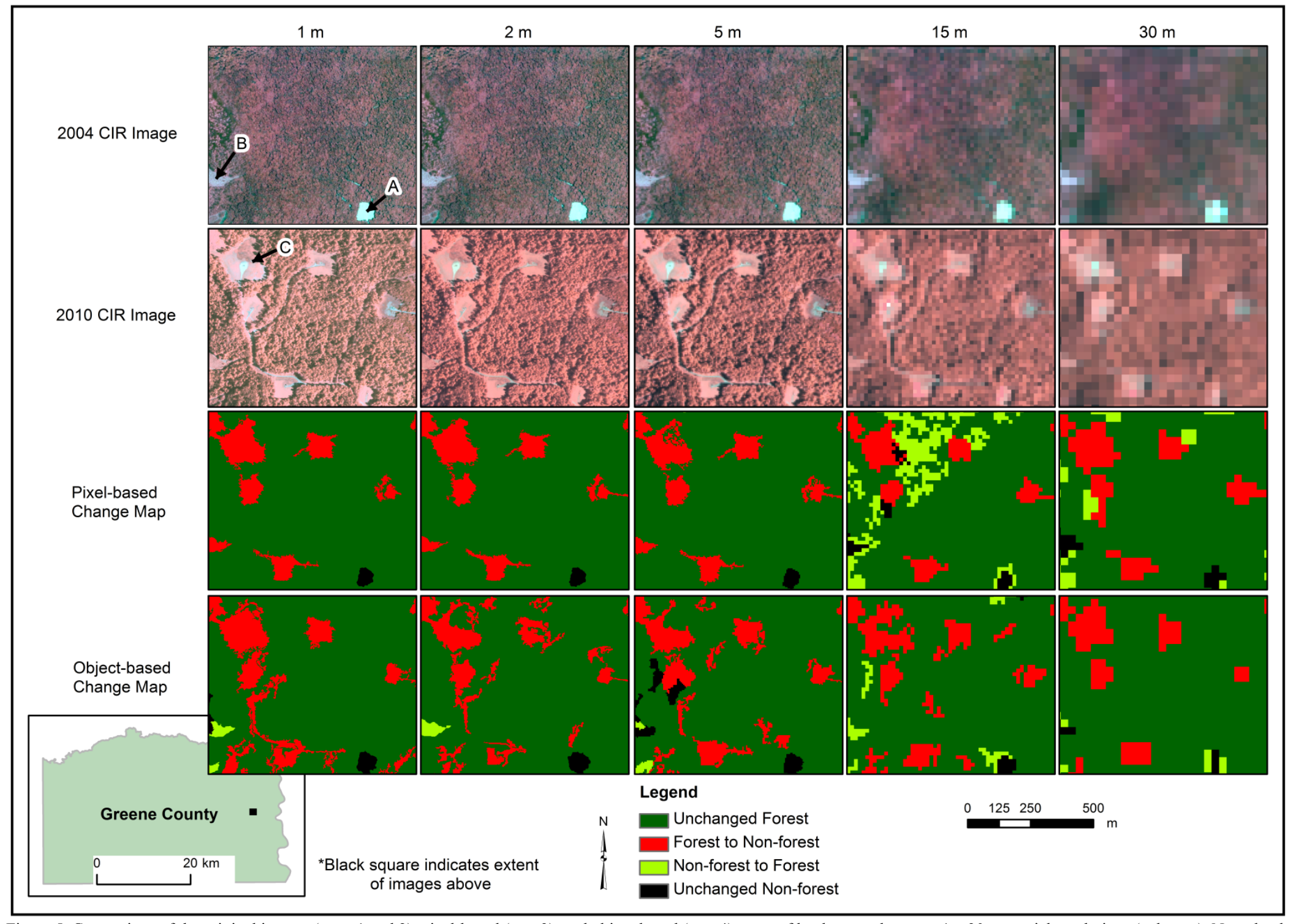

Figure 5. Comparison of the original images (rows 1 and 2), pixel-based (row 3), and object-based (row 4) maps of land cover change at $1-30 \mathrm{~m}$ spatial resolutions (columns). Note that both the pixel-based and object-based overlay maps have been filtered to eliminate all land cover patches less than $1800 \mathrm{~m}^{2}$. 


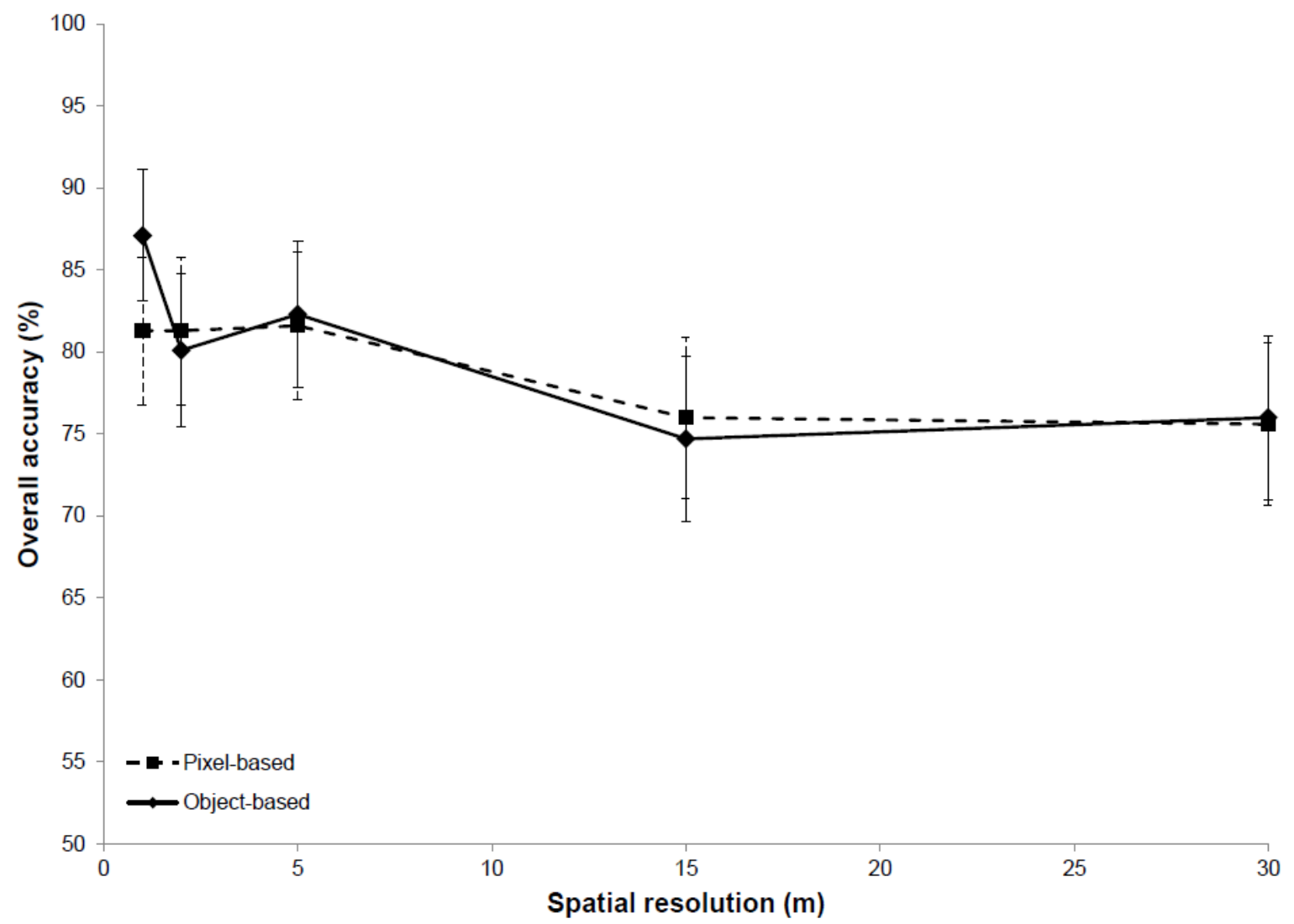

Figure 6. Comparison of overall accuracy of land cover change maps for pixel-based and object-based classification methods of 5 spatial resolutions. Error bars indicate $95 \%$ confidence interval. 


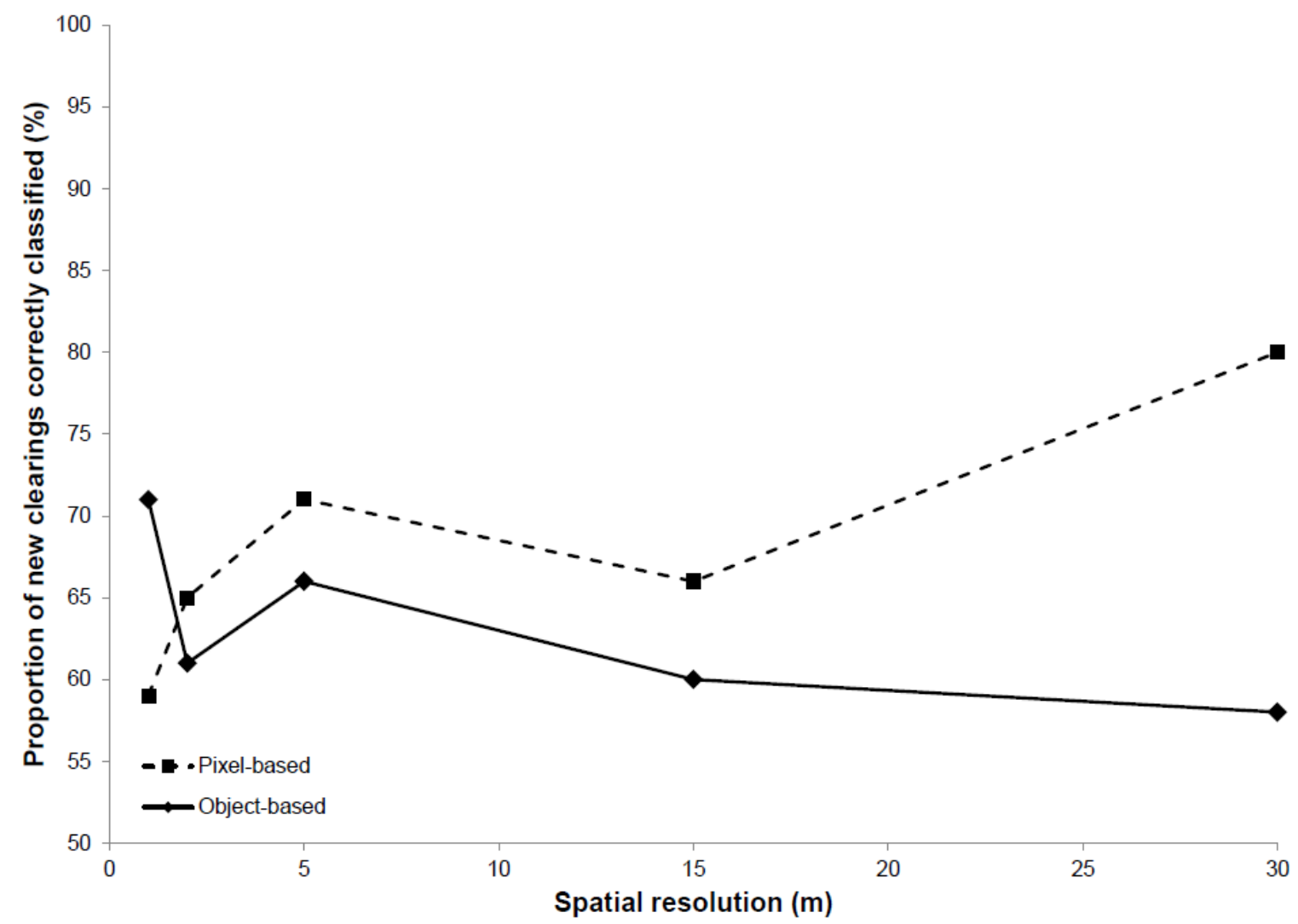

Figure 7. Accuracy comparison of the proportion of correctly identified land cover change for 180 well clearings for pixel-based and object-based classification methods. 
(a)

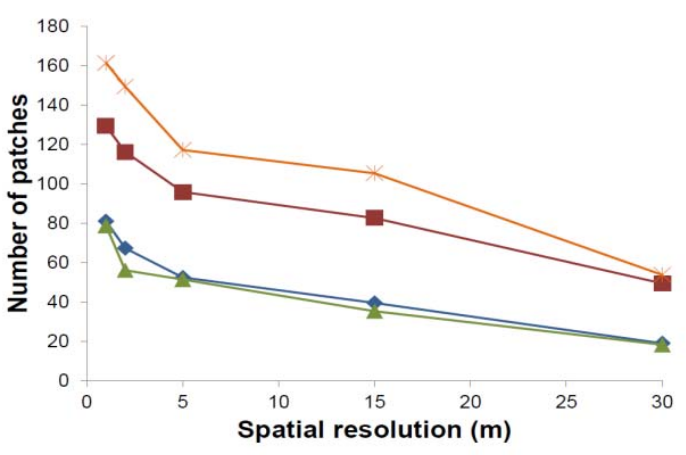

(c)

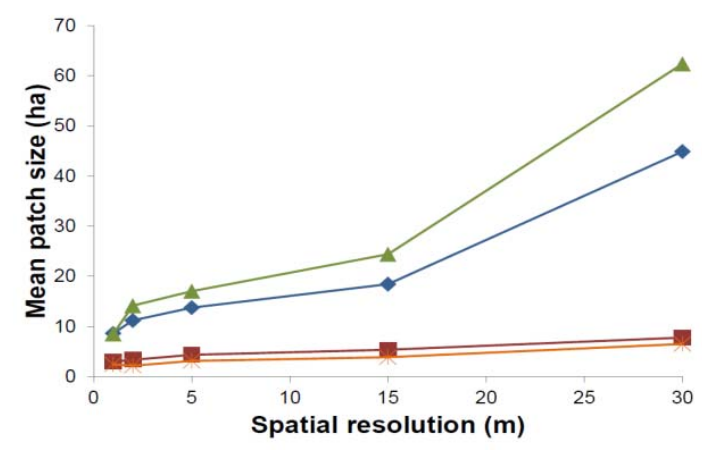

(e)

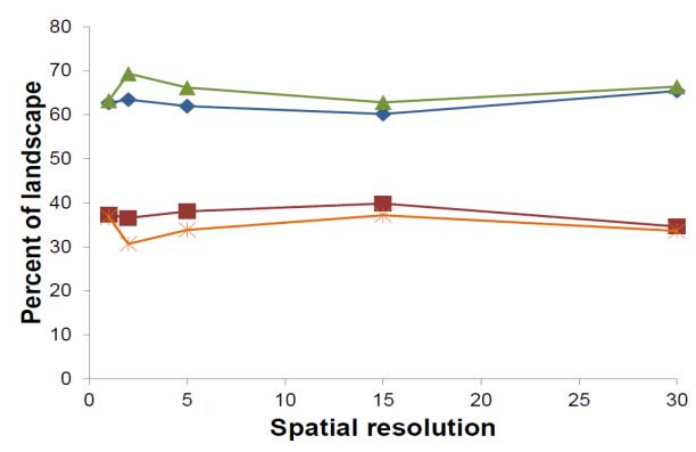

(b)

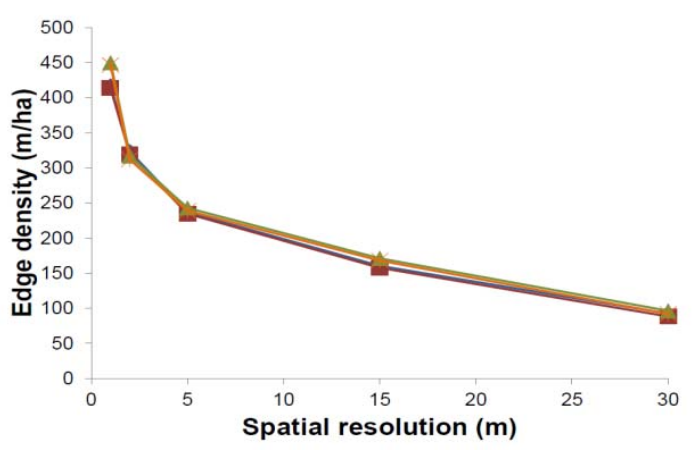

(d)

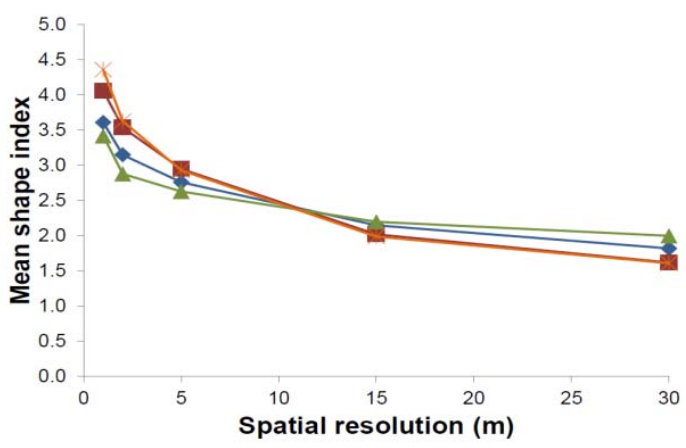

Figure 8. Scalograms showing landscape metric scaling relations across selected spatial resolutions $(1 \mathrm{~m}, 2 \mathrm{~m}, 5 \mathrm{~m}$, $15 \mathrm{~m}$, and $30 \mathrm{~m}$ ). Metrics are shown for Forest and Non-forest classes for 2004 and 2010 classifications. Compare to Table 1. 

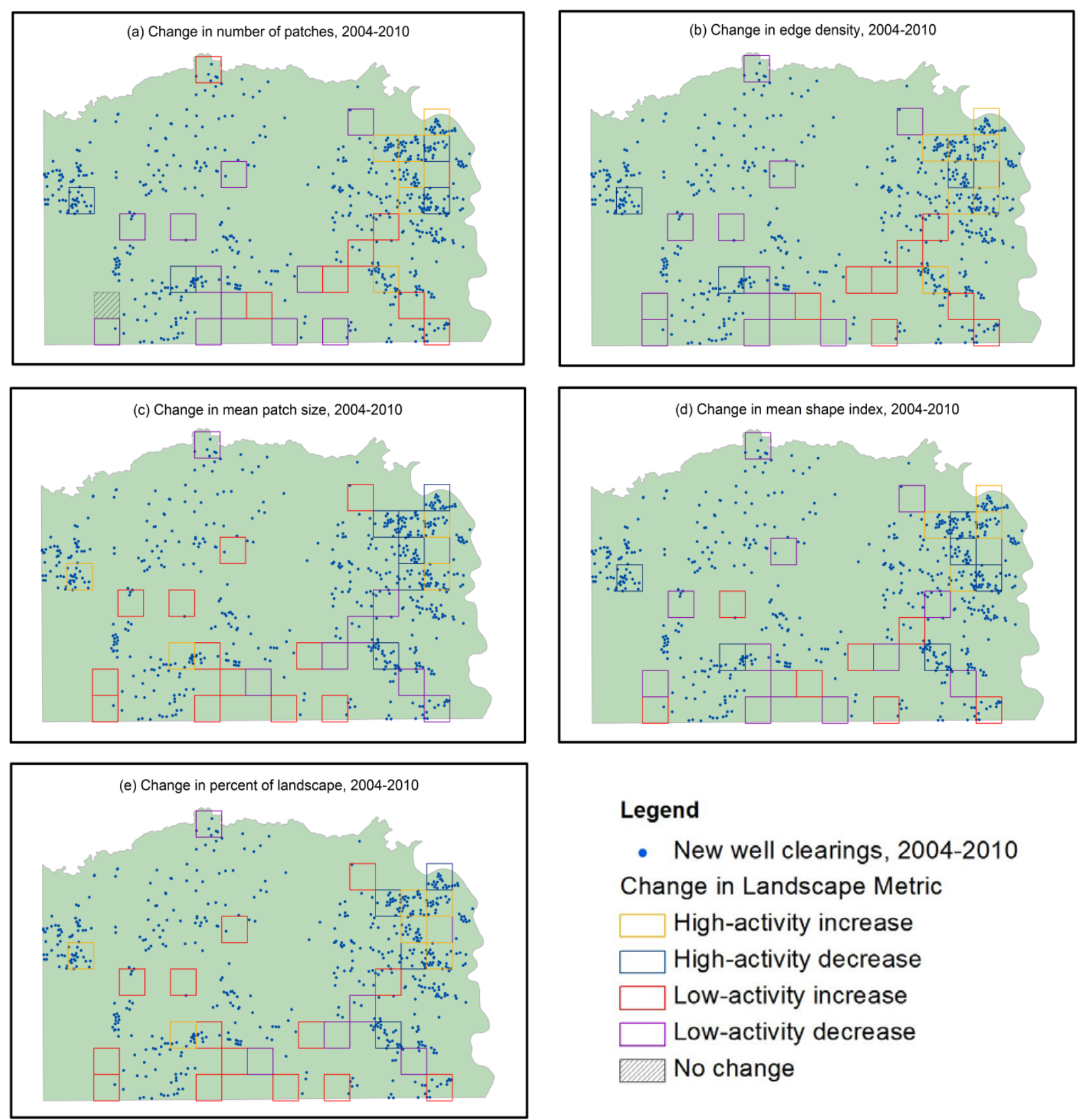

\section{Legend}

- New well clearings, 2004-2010

Change in Landscape Metric

High-activity increase

High-activity decrease

Low-activity increase

Low-activity decrease

No change

Figure 9. Maps of changes in landscape metrics between 2004 and 2010 for classification of $5 \mathrm{~m}$ data, for 30 random quadrat samples. (a) Number of patches, (b) Edge density, (c) Mean patch size, (d) Mean shape index, (e) Percent of landscape. High-activity quadrats are those with more than 12 wells. 
Table 1. Selected landscape metrics, definitions, and previous findings regarding scaling relations of landscape metrics at coarse resolutions

\begin{tabular}{|c|c|c|c|}
\hline \multirow[b]{2}{*}{ Metric } & \multirow[b]{2}{*}{ Definition } & \multicolumn{2}{|c|}{ Scaling Relationships } \\
\hline & & Wu et al. 2002 & Wu 2004 \\
\hline $\begin{array}{l}\text { Number of patches } \\
\text { (\#PAT) }\end{array}$ & $\begin{array}{l}\text { Total number of patches in the landscape for } \\
\text { forest class }\end{array}$ & $\begin{array}{l}\text { Predictable, decreasing power law } \\
\text { function }\end{array}$ & Consistent, robust \\
\hline Edge Density (ED) & $\begin{array}{l}\text { Length of edge for forest class relative to the } \\
\text { landscape area. Reported in } \mathrm{m} / \mathrm{ha}\end{array}$ & $\begin{array}{l}\text { Predictable, decreasing power law } \\
\text { function }\end{array}$ & Consistent, robust \\
\hline $\begin{array}{l}\text { Mean Patch Size } \\
\text { (MPS) }\end{array}$ & Average patch area for forest class patches $\left(\mathrm{m}^{2}\right)$ & Predictable, increasing power law function & Consistent, less robust \\
\hline $\begin{array}{l}\text { Mean Shape Index } \\
\text { (MSI) }\end{array}$ & $\begin{array}{l}\text { Shape complexity of forest patches. MSI equals } 1 \\
\text { when patch is square and increases with } \\
\text { increasing shape irregularity. }\end{array}$ & $\begin{array}{l}\text { Erratic response, relatively insensitive to } \\
\text { changing scale }\end{array}$ & Inconsistent \\
\hline $\begin{array}{l}\% \text { of Landscape } \\
\text { (PLAND) }\end{array}$ & $\begin{array}{l}\text { Percentage of total landscape made up of forest } \\
\text { patches }\end{array}$ & Not included & Inconsistent \\
\hline
\end{tabular}


Table 2. Overall accuracy, producer's accuracy, user's accuracy, quantity disagreement, and allocation disagreement for maps of land cover change (a), (c), (e), (g), \& (i) pixel-based and (b), (d), (f), (h), \& (j) object-based classification methods at $1 \mathrm{~m}, 2 \mathrm{~m}, 5 \mathrm{~m}, 15 \mathrm{~m}$, and $30 \mathrm{~m}$ spatial scales. *Note object-based classifications have area-weighted overall accuracy but otherwise accuracies are reported on a per-object (pixel) basis.

\begin{tabular}{|c|c|c|c|c|c|c|c|c|c|c|c|c|c|c|}
\hline \multirow{3}{*}{$\begin{array}{c}\text { a) } \\
\text { Classified }\end{array}$} & \multicolumn{7}{|c|}{ Accuracy measures for $1 \mathrm{~m}$ pixel-based map } & \multicolumn{7}{|c|}{ Accuracy measures for $1 \mathrm{~m}$ object-based map } \\
\hline & \multicolumn{7}{|c|}{ Reference } & \multirow[t]{2}{*}{ Classified } & \multicolumn{6}{|c|}{ Reference } \\
\hline & & 1 & 2 & 3 & 4 & Total & User's (\%) & & 1 & 2 & 3 & 4 & Total & User's (\%) \\
\hline & 1 & 174 & 1 & 1 & 17 & 193 & 90 & 1 & 156 & 0 & 1 & 11 & 168 & 93 \\
\hline & 2 & 1 & 6 & 0 & 15 & 22 & 27 & 2 & 5 & 4 & 0 & 5 & 14 & 29 \\
\hline & 3 & 9 & 0 & 2 & 7 & 18 & 11 & 3 & 9 & 0 & 0 & 3 & 12 & 0 \\
\hline & 4 & 5 & 0 & 0 & 62 & 67 & 93 & 4 & 5 & 1 & 0 & 80 & 86 & 93 \\
\hline Total & & 189 & 7 & 3 & 101 & 300 & & Total & 175 & 5 & 1 & 99 & 280 & \\
\hline Producer's $(\%$ & & 92 & 86 & 67 & 61 & & & Producer's (\%) & 89 & 80 & 0 & 81 & & \\
\hline \multirow{3}{*}{\multicolumn{8}{|c|}{$\begin{array}{l}\text { Overall Accuracy }=81.3 \% \\
\text { Quantity Disagreement }=0.11 \\
\text { Allocation Disagreement }=0.07\end{array}$}} & \multicolumn{7}{|c|}{ Area-weighted Overall Accuracy $=87.1 \%$} \\
\hline & & & & & & & & Quantity Disagre & ement & 0.07 & & & & \\
\hline & & & & & & & & Allocation Disag & reemen & $=0.0^{7}$ & & & & \\
\hline c) & \multicolumn{7}{|c|}{ Accuracy measures for $2 \mathrm{~m}$ pixel-based map } & Acc & \multicolumn{6}{|c|}{ Accuracy measures for $2 \mathrm{~m}$ object-based map } \\
\hline \multirow[t]{6}{*}{ Classified } & \multicolumn{7}{|c|}{ Reference } & Classified & Refe & & & & & \\
\hline & & 1 & 2 & 3 & 4 & Total & User's (\%) & & 1 & 2 & 3 & 4 & Total & User's (\%) \\
\hline & 1 & 176 & 1 & 1 & 18 & 197 & 89 & 1 & 166 & 3 & 1 & 5 & 175 & 95 \\
\hline & 2 & 4 & 5 & 0 & 17 & 26 & 19 & 2 & 4 & 1 & 0 & 5 & 10 & 10 \\
\hline & 3 & 5 & 0 & 2 & 5 & 12 & 17 & 3 & 15 & 0 & 0 & 22 & 37 & 0 \\
\hline & 4 & 4 & 0 & 0 & 61 & 65 & 94 & 4 & 3 & 1 & 0 & 69 & 73 & 95 \\
\hline Total & & 189 & 7 & 3 & 101 & 300 & & Total & 188 & 5 & 1 & 101 & 295 & \\
\hline Producer's ( $\%$ & & 93 & 71 & 67 & 60 & & & Producer's (\%) & 88 & 20 & 0 & 68 & & \\
\hline Overall Accu & urac & $=81$. & & & & & & Area-weighted $\mathrm{C}$ & verall & curac & $=80$ & & & \\
\hline Quantity Dis & sagre & ment & 0.12 & & & & & Quantity Disagre & ement & .14 & & & & \\
\hline Allocation D & Disag & eeme & $=0.07$ & & & & & Allocation Disag & reemen & $=0.06$ & & & & \\
\hline e) & Acc & Iracy & easure & for 5 & pixel & ased ma & & Acc & uracy 1 & asur & for: & objec & based $\mathbf{n}$ & \\
\hline Classified & & Refe & & & & & & Classified & Refer & & & & & \\
\hline & & 1 & 2 & 3 & 4 & Total & User's (\%) & & 1 & 2 & 3 & 4 & Total & User's (\%) \\
\hline & 1 & 176 & 1 & 1 & 17 & 195 & 90 & 1 & 162 & 2 & 1 & 10 & 175 & 93 \\
\hline & 2 & 7 & 6 & 0 & 16 & 29 & 21 & 2 & 3 & 4 & 0 & 1 & 8 & 50 \\
\hline & 3 & 3 & 0 & 2 & 7 & 12 & 17 & 3 & 15 & 0 & 3 & 19 & 37 & 8 \\
\hline & 4 & 3 & 0 & 0 & 61 & 64 & 95 & 4 & 3 & 0 & 0 & 73 & 76 & 96 \\
\hline Total & & 189 & 7 & 3 & 101 & 300 & & Total & 183 & 6 & 4 & 103 & 296 & \\
\hline Producer's ( $\%$ & & 93 & 86 & 67 & 60 & & & Producer's (\%) & 89 & 67 & 75 & 71 & & \\
\hline Overall Accu & urac & $=81$. & & & & & & Area-weighted $\mathrm{C}$ & verall & curac & $=82$ & & & \\
\hline Quantity Dis & sagre & ment & 0.12 & & & & & Quantity Disagre & ement & 0.12 & & & & \\
\hline Allocation D & Disag & eeme & $=0.06$ & & & & & Allocation Disag & reemen & $=0.06$ & & & & \\
\hline g) & Acc & Iracy & easure & for 1 & pixe & pased $\mathbf{m}$ & & Acc & uracy 1 & asur & for & n obje & -based & \\
\hline Classified & & Refe & & & & & & Classified & Refer & & & & & \\
\hline & & 1 & 2 & 3 & 4 & Total & User's (\%) & & 1 & 2 & 3 & 4 & Total & User's (\%) \\
\hline & 1 & 148 & 0 & 1 & 12 & 161 & 92 & 1 & 134 & 2 & 1 & 4 & 141 & 95 \\
\hline & 2 & 5 & 7 & 0 & 6 & 18 & 39 & 2 & 21 & 5 & 0 & 8 & 34 & 15 \\
\hline & 3 & 28 & 0 & 2 & 12 & 42 & 5 & 3 & 20 & 0 & 2 & 15 & 37 & 5 \\
\hline & 4 & 8 & 0 & 0 & 71 & 79 & 90 & 4 & 7 & 0 & 0 & 76 & 83 & 92 \\
\hline Total & & 189 & 7 & 3 & 101 & 300 & & Total & 182 & 7 & 3 & 103 & 295 & \\
\hline Producer's ( $\%$ & & 78 & 100 & 67 & 70 & & & Producer's (\%) & 74 & 71 & 67 & 74 & & \\
\hline Overall Accu & urac & $=76$. & & & & & & Area-weighted $\mathrm{C}$ & verall & curac & $=74$ & & & \\
\hline Quantity Dis & sagr & ment & & & & & & Quantity Disagre & ement & .21 & & & & \\
\hline Allocation D & Disas & eeme & $=0.07$ & & & & & Allocation Disag & reemen & $=0.06$ & & & & \\
\hline i) & Acc & Iracy & easur & for 3 & pixe & pased $\mathbf{m}$ & & Acc & uracy & asur & for: & n obje & -based & \\
\hline Classified & & Refe & & & & & & Classified & Refe & & & & & \\
\hline & & 1 & 2 & 3 & 4 & Total & User's (\%) & & 1 & 2 & 3 & 4 & Total & User's (\%) \\
\hline & 1 & 144 & 0 & 1 & 10 & 155 & 93 & 1 & 142 & 17 & 18 & 7 & 184 & 77 \\
\hline & 2 & 14 & 6 & 0 & 9 & 29 & 21 & 2 & 9 & 7 & 0 & 9 & 25 & 28 \\
\hline & 3 & 11 & 0 & 1 & 6 & 18 & 6 & 3 & 0 & 0 & 4 & 12 & 16 & 25 \\
\hline & 4 & 20 & 1 & 1 & 76 & 98 & 78 & 4 & 0 & 0 & 0 & 68 & 68 & 100 \\
\hline Total & & 189 & 7 & 3 & 101 & 300 & & Total & 151 & 24 & 22 & 96 & 293 & \\
\hline Producer's ( & $\%)$ & 76 & 86 & 33 & 75 & & & Producer's (\%) & 94 & 29 & 18 & 71 & & \\
\hline Overall Accu & urac & $=75$. & & & & & & Area-weighted $\mathrm{C}$ & verall & curac & $=76$ & & & \\
\hline Quantity Dis & sagr & ment & 0.12 & & & & & Quantity Disagre & ement & .12 & & & & \\
\hline Allocation D & Disa: & eeme & $=0.12$ & & & & & Allocation Disag & reemen & $=0.13$ & & & & \\
\hline
\end{tabular}


Table 3. Wilcoxon signed ranks test of landscape metric changes between 2004 and 2010 for all quadrat samples $(\mathrm{n}=30)$

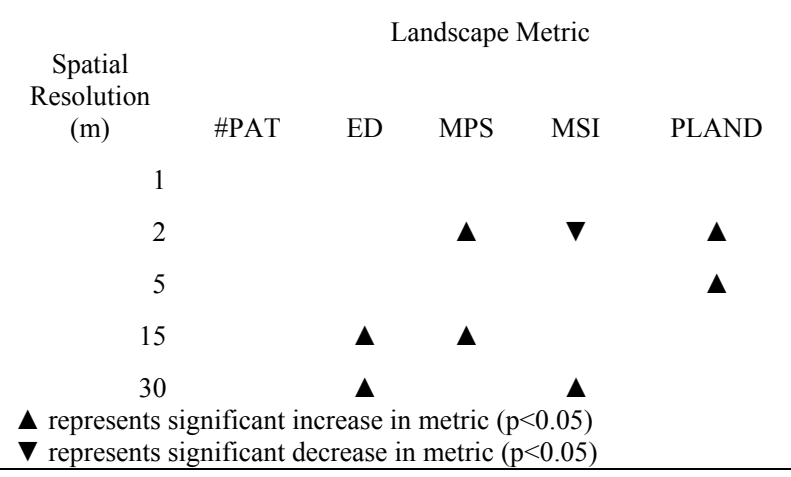

Table 4. Wilcoxon signed ranks test of landscape metric changes between 2004 and 2010 for low-activity quadrat samples $(n=20)$

$\begin{gathered}\text { Spatial } \\ \begin{array}{c}\text { Resolution } \\ (\mathrm{m})\end{array} \\ \end{gathered}$
1
2

Table 5. Wilcoxon signed ranks test of landscape metric changes between 2004 and 2010 for high-activity quadrat samples $(\mathrm{n}=10)$

$\begin{gathered}\text { Spatial } \\ \text { Resolution } \\ (\mathrm{m})\end{gathered}$

1




\section{Appendix 1: Example object-based ruleset}

- Object Segmentation

F.... 5 [shape:0.1 compct::0.5] creating 'New Level'

|.. - Classify Non Forest using Brightness

1. unclassified with Brightness $<=105$ at New Level: Non Forest

1.t. unclassified with Brightness $>=162$ at New Level: Non Forest

1... - Classify Non Forest Using NDVI

I. unclassified with NDVI ratio $<=0.225$ at New Level: Non Forest

|.. - Classify Forest using NDVI and NIR SD

1. unclassified with NDVI ratio $>=0.24$ and Standard deviation near infrared $>=5.5$ at New Level: Forest

|... - Classify Non Forest using Green and Green SD

11. unclassified with Mean green > 122 and Standard deviation green $<=3.8$ at New Level: Non Forest

1... - Classify Forest using Brightness and mean Red

1. unclassified with Brightness $<=155$ and Mean red $<=130$ at New Level: Forest

1... - Classify Unclassified as non Forest

unclassified at New Level: Non Forest

|... - Merge Unclassified

Non Forest with Brightness $=0$ at New Level: unclassified

wov unclassified at New Level: merge region

1... - Merge Forest and Non Forest Polygons

vor. Non Forest at New Level: merge region

vor. Forest at New Level: merge region

Figure 10. Example of object-based ruleset using eCognition Developer

The first step in the object-based classification is image segmentation. Next, rules were developed to classify Forest and Non-Forest objects. The first rule uses Brightness to classify very dark objects such as water and coal, and bright objects like concrete and some rooftops. Next, Normalized Difference Vegetation Index (NDVI) values were incorporated to classify Non-forested objects below a specified threshold, and then NDVI and NIR standard deviation were used to classify Forest objects that met a certain criterion. The use of standard deviation to classify objects is helpful for separating Forest from other Non-Forest vegetation objects because, at appropriate segmentation scales, Forest objects are more heterogeneous than other vegetation land covers (e.g. fields) and thus have a coarser texture which increases the standard deviation. The remaining rules exploit similar relationships to classify Forest and Non-Forest land cover types. 


\section{Appendix 2: Image acquisition date map}

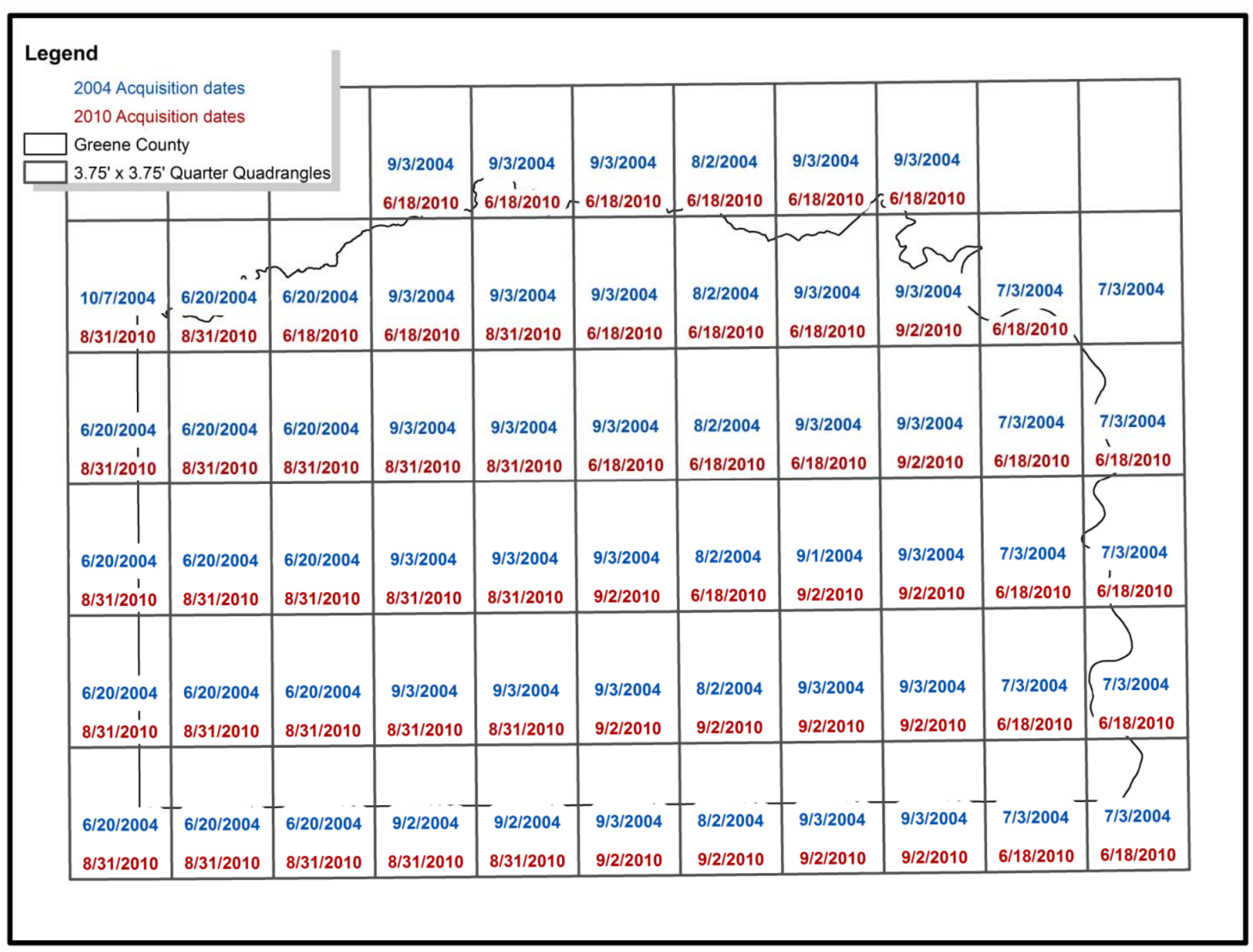

Figure 11. Map of image acquisition dates by year for each $3.75^{\prime} \times 3.75^{\prime}$ quarter quadrangle within study area 